MICHAEL T. KILEY

Federal Reserve Board

JOHN M. ROBERTS

Federal Reserve Board

\title{
Monetary Policy in a Low Interest Rate World
}

\begin{abstract}
Nominal interest rates may remain substantially below the averages of the last half century, because central banks' inflation objectives lie below the average level of inflation, and estimates of the real interest rate that are likely to prevail over the long run fall notably short of the average real interest rate experienced during this period. Persistently low nominal interest rates may lead to more frequent and costly episodes at the effective lower bound (ELB) on nominal interest rates. We revisit the frequency and potential costs of such episodes in a world of low interest rates, using both a dynamic stochastic general equilibrium (DSGE) model and the Federal Reserve's largescale econometric model, the FRB/US model. Four main conclusions emerge. First, monetary policy strategies based on traditional, simple policy rules lead to poor economic performance when the equilibrium interest rate is low, with economic activity and inflation more volatile and systematically falling short of desirable levels. Moreover, the frequency and length of ELB episodes under such policy approaches are estimated to be significantly higher than in previous studies. Second, a risk adjustment to a simple rule-whereby monetary policymakers are more accommodative, on average, than prescribed by the rule-ensures that inflation averages its 2 percent objective, and requires that policymakers systematically seek inflation near 3 percent when the ELB is not binding. Third, commitment strategies, whereby monetary accommodation is not removed until either inflation or economic activity overshoots its longrun objective, are very effective in both the DSGE and FRB/US models. And
\end{abstract}

Conflict of Interest Disclosure: The authors did not receive financial support from any firm or person for this paper or from any firm or person with a financial or political interest in this paper. They are currently not officers, directors, or board members of any organization with an interest in this paper. The analysis and conclusions set forth are those of the authors and do not indicate concurrence by the Federal Reserve Board or other members of its staff. 
fourth, our simulation results suggest that the adverse effects on economic and price stability associated with the ELB may be substantial at inflation targets near 2 percent if the equilibrium real interest rate is low and monetary policy follows a traditional approach. Whether such adverse effects could justify a higher inflation target depends upon the degree to which monetary policy strategies that differ substantially from such traditional approaches are feasible, and an assessment of a broader array of the inflation target's effects on economic welfare.

uring the low inflation period of recent decades, the effective lower bound (ELB) across Europe, Japan, and the United States has been binding for a large fraction of the time, impeding macroeconomic performance. ELB episodes may become more frequent and costly in the future, given that nominal interest rates may remain substantially below the norms of the last 50 years.

Heightening this concern is the possibility that structural factors have depressed - and will continue to depress for some time - the level of the short-term real interest rate consistent with price stability and economic activity at its potential level. This level of the real interest rate—often termed the equilibrium real interest rate, $r^{*}$-may have fallen for many reasons, including a slower rate of technological progress; the demographic transitions associated with the aging of the baby boom generation, increased longevity, and changes in the dependency ratio; the overhang from an excessive buildup of household debt through the mid-2000s; and shifts in the demand for safe and liquid assets. ${ }^{1}$ A number of empirical studies document a decline in $r^{*}$ : Although there is considerable uncertainty about the current level and its future trajectory, many studies-including the paper by Marco Del Negro and others (2017) in the present volumesuggest that $r^{*}$ may be near 1 percent (or lower) at an annual rate, 1 to 2 percentage points below that average real interest rate in the period since the middle of the last century.

The potential decline in the equilibrium real interest rate has been accompanied by a decline in the level of inflation expected to prevail over the longer run-a decline owing, in large part, to the shift in central banks' objectives toward targeting a level of inflation near 2 percent. Figure 1

1. In addition to Del Negro and others (2017), discussions of factors that may contribute to a lower $r^{*}$ include those by Hamilton and others (2015); Gagnon, Johanssen, and LopezSalido (2016); and Eggertsson, Mehrotra, and Robbins (2017). 
Figure 1. The Nominal Federal Funds Rate, Inflation, and Long-Run Inflation Expectations, 1965-2016

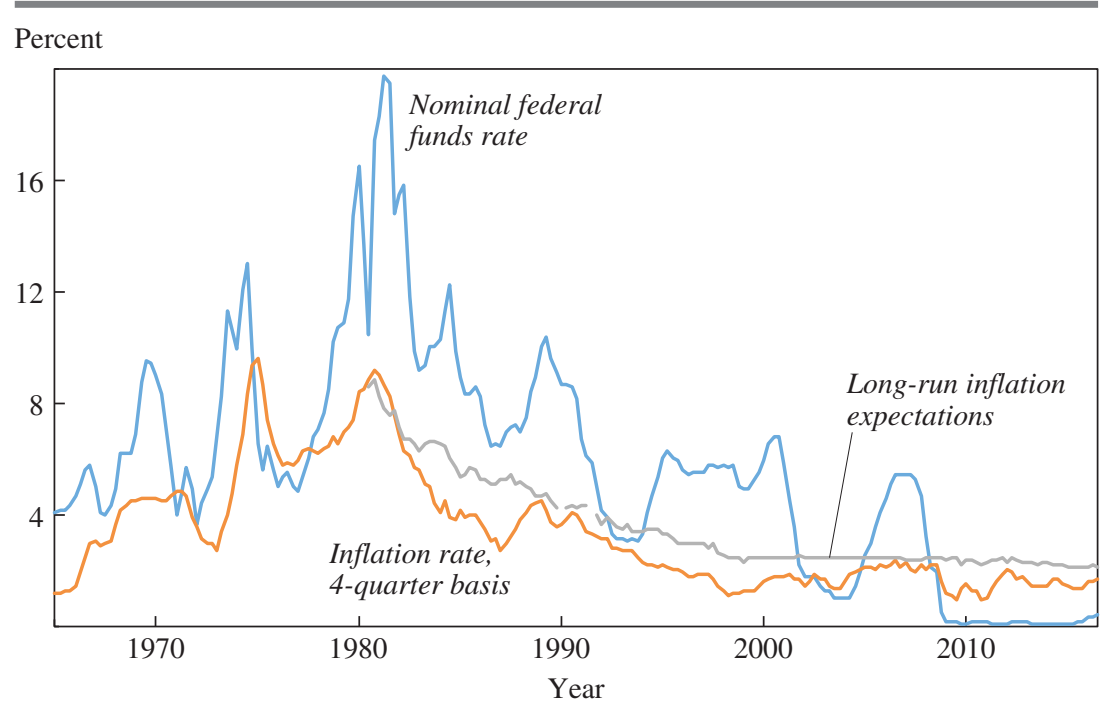

Source: Federal Reserve Board.

graphs the evolution of the nominal effective federal funds rate, inflation, and a survey measure of long-term inflation expectations. The downward drift in nominal rates and inflation is striking, and points to the possibility that nominal interest rates may remain persistently below the averages of the past half century.

A simple thought experiment highlights the potential importance of persistently lower interest rates for the frequency of the ELB. During the period from 1960 to 2007, the nominal federal funds rate averaged about 6 percent, with a standard deviation of $3 \frac{1}{4}$ percentage points. Figure 2 presents the probability density function of a variable with this mean and standard deviation, assuming a normal distribution. As can be seen at the intersection of the density function and the shaded region that begins at zero, this distribution implies that an observer might expect an ELB of zero to bind rarely (less than 5 percent of the time): During the 48 years from 1960 to 2007, this expected event—about two years of the nominal interest rate below zero- did not occur, but was realized soon thereafter.

The other density function maintains the standard deviation of the nominal interest rate, but assumes that its mean is lower, at 3 percent. Such lower values could stem from an inflation target below the mean of inflation from 
Figure 2. Probability Density Functions for Alternative Steady-State Nominal Interest Rates under an Assumption of Normality

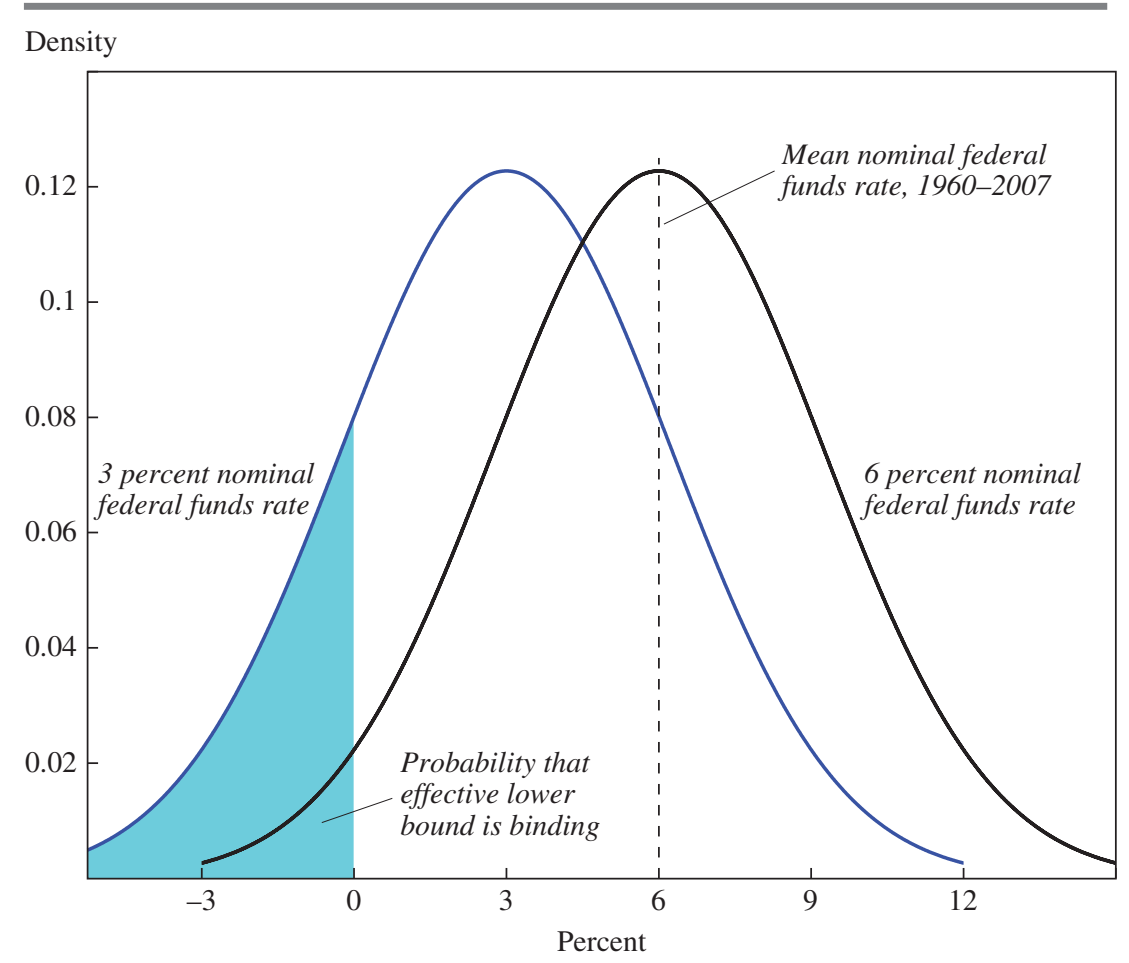

Source: Authors' calculations.

1960 to 2007, because core personal consumption expenditures (PCE) price inflation averaged a bit more than $3 \frac{1}{2} 2$ percent during that period and most target rates of inflation in advanced economies are notably below this level. Alternatively, a lower steady-state nominal interest rate could reflect the decline in the equilibrium real interest rate. Whatever the cause, a decline in the steady-state nominal interest rate implies a sharply rising incidence of the ELB. For example, a steady-state nominal interest rate of 3 percent is consistent with an inflation target of 2 percent and $r^{*}$ equal to 1 percent, and, according to the corresponding density function, would imply nominal interest rates below zero 18 percent of the time. A binding ELB of this magnitude would lead to a deterioration in economic activity and inflationand thereby amplify the costs and frequency of the ELB. For example, one possible consequence is the inflation target of 2 percent not being met consistently-which we discuss in detail below. 
To quantify the magnitude of this amplification and to assess strategies to address it, we employ simulations of macroeconomic models. Alternative macroeconomic models may have different implications for the degree to which the ELB may affect economic and price stability. We use two models - the Federal Reserve Board's FRB/US model, and a dynamic stochastic general equilibrium (DSGE) model. As emphasized by Flint Brayton, Thomas Laubach, and David Reifschneider (2014) and JeanPhilippe Laforte and John Roberts (2014), the FRB/US model is extensively used in monetary policy analysis at the Federal Reserve and captures features of the economy that reflect consensus views across macroeconomists, but it is not strictly "micro-founded," in the manner used in many academic analyses. The DSGE model we use - that of Jesper Lindé, Frank Smets, and Rafael Wouters (2016) — is much smaller than FRB/US but also shares a number of features with FRB/US, including similar contours of the effects of monetary policy on economic activity and inflation. ${ }^{2}$ In spite of these similarities, the DSGE model also features substantially greater amplification of shocks at the ELB and a more powerful role for forward guidance regarding monetary policy to affect outcomes. These differences allow us to examine the robustness of certain model predictions and policy strategies related to the effects of the ELB, and hence provide insights beyond studies using either the FRB/US model or a DSGE model in isolation.

Our simulations suggest that an economy in which the steady-state nominal interest rate equals 6 percent-about the average value for the nominal federal funds rate from 1960 to 2007-will rarely encounter an ELB of zero under a policy rule estimated on U.S. data or under a simple benchmark rule, which takes the form of John Taylor's (1993) rule. ${ }^{3}$ As noted in earlier work with the FRB/US model (Reifschneider and Williams 2000; Williams 2009; Chung and others 2012), performance

2. Boivin, Kiley, and Mishkin (2010) highlight the similarities and differences in the monetary policy transmission mechanism across models like the FRB/US model and DSGE models.

3. As we discuss more thoroughly below, we employ a simple rule that responds more forcefully to the output gap than the original Taylor (1993) rule, as considered by Taylor (1999) and suggested by Bernanke (2015b). Yellen (2017) labeled this rule the "balanced approach." It is among the rules that began to be regularly reported to the FOMC starting in 2004; see https://www.federalreserve.gov/monetarypolicy/fomchistorical2004.htm. Bernanke (2015b) reported that, in his experience, the Federal Open Market Committee paid more attention to rules such as the balanced approach rule than to other related rules. The specific coefficient on the output gap is not central to our qualitative or quantitative conclusions. 
under an estimated rule or the simple rule deteriorates sharply in FRB/ US for steady-state nominal interest rates of 4 percent or less, as would be implied by an inflation target of 2 percent and values of $r^{*}$ of 2 percent or less. In such circumstances, the ELB binds often and inflation falls systematically short of the 2 percent objective; in addition, output is, on average, below its potential level.

Quantitatively, we find that the incidence and severity of ELB episodes are notably larger than in previous research. Consider first work with the FRB/US model. In our analysis, output falls 1 percent below potential, on average, and the ELB binds two-fifths of the time when the long-run nominal interest rate is 3 percent; this estimate of ELB incidence compares with an estimate of 16 percent under the simple rule and "worst case" assumption of John Williams (2009). Earlier work with DSGE models was also quite sanguine about the consequences of the ELB for macroeconomic performance-see, for example, Olivier Coibion, Yuriy Gorodnichenko, and Johannes Wieland (2012).

As we discuss in more detail below, we find more frequent and severe ELB episodes than earlier analyses using FRB/US or DSGE models, for several reasons. One is that we consider lower values of the equilibrium federal funds rate than some earlier studies. More important, these earlier studies often assumed policy rules that differ in important ways from the canonical simple rules, including implicit channels generating commitments or forward guidance. For example, the rules considered by Williams (2009) include a fallback mechanism for providing the accommodation precluded by an ELB that substantially mitigates the adverse effects of the ELB. Similarly, Coibion, Gorodnichenko, and Wieland (2012) construct a "shadow" interest rate that keeps track of accommodation forgone because of the ELB, and commits to make up some of this forgone accommodation. Commitments are effective in both the FRB/US and DSGE models, and hence a good part of the sanguine assessments of the effects of the ELB in previous analyses are owing to their commitment assumptions.

To address the sizable consequences of the ELB, the first strategy we consider is a risk adjustment to the policy rule, in which the short-term nominal interest rate is set, on average, at a level below the value prescribed by a traditional simple rule in order to ensure that inflation equals, on average, an assumed inflation target of 2 percent. Earlier work-including that by Reifschneider and Williams (2000), Williams (2009), and Taisuke Nakata and Sebastian Schmidt (2016)—considered a similar adjustment. We find moderate risk adjustments, on the order of $1 / 2$ to 1 percentage point, ensure that inflation averages 2 percent when $r^{*}$ is as low as 1 percent and 
the inflation target is 2 percent. Such risk adjustments imply that, in periods when the ELB is not binding, inflation averages more than 2 percent. Thus, the efficacy of such policies in achieving an inflation target of 2 percent hinges on policymakers pursuing inflation levels that are notably above 2 percent - in our model simulations, near 3 percent—during periods when the ELB does not bind.

Although the risk-adjusted simple rule allows the central bank to achieve its inflation target, the economy nonetheless encounters the ELB with greater frequency at lower levels of average interest rates, and economic performance is worse. One response to these challenges - voiced by Olivier Blanchard, Giovanni Dell'Ariccia, and Paolo Mauro (2010); Laurence Ball (2014); and Ball and others (2016) — is for a central bank to consider a higher target for inflation. Such a shift would likely lower the frequency of ELB episodes and their undesirable effects. At the same time, a higher inflation target, if achieved, would be accompanied by the costs of higher average inflation. There is a great deal of controversy about the importance of these costs. Our simulations do not provide insights about such costs. However, they demonstrate the benefits of different monetary policy strategies for reduced volatility and skewness of economic outcomes. To illustrate how an assessment of the benefits and costs associated with a higher inflation target depend on the effects of the ELB on economic stabilization, we posit an ad hoc loss function that is typical in the literature and we explore alternative assumptions about the costs of inflation and output deviations from socially optimal levels in such a framework. Overall, our simulation results suggest that the adverse effects on economic and price stability associated with the ELB may be substantial at inflation targets near 2 percent if $r^{*}$ is low and monetary policy follows a traditional approach, as embedded in rules of the Taylor (1993) form. Whether such adverse effects could justify a higher inflation target depends upon the degree to which monetary policy strategies that differ substantially from such traditional approaches are feasible and on an assessment of a broader array of the inflation target's effects on economic welfare.

In light of the potential problems associated with either a risk adjustment to a simple rule or a higher inflation target assuming a simple rule, we also consider policy strategies that imply substantial changes in the manner in which accommodation is delivered and that include a role for commitments by the central bank-akin to the "Odyssean" forward guidance described by Jeffrey Campbell and others (2012) — to make up any accommodation precluded by the ELB. A strategy we consider is a policy rule whereby changes in (rather than the level of) the nominal interest rate are linked 
to deviations of inflation and output from the objective. Such an approach implies that nominal interest rates are not raised from the ELB (once it is reached) until either inflation or output overshoots its objective. Such a policy improves outcomes, but still shows sizable deterioration in economic performance in an environment of low steady-state nominal interest rates. The addition of a commitment to track a shadow rate, which captures the accumulated stock of forgone accommodation induced by the ELB, essentially eliminates the costs of an ELB. These results highlight how commitments to maintain accommodation until inflation or economic activity overshoots its objective may not be sufficient to eliminate the adverse consequences of an ELB; instead, such policies may need to be accompanied by additional commitments that remain accommodative for an even longer period (akin to the make-up policies suggested by Reifschneider and Williams 2000). We note the close relationship between such a change rule and price level or nominal income approaches.

The efficacy of commitment strategies implies that the need to consider alternatives such as a higher inflation target is greatly reduced, if such an approach is credible with the public and shifts expectations in the manner predicted by the models. A crucial question, then, is whether a central bank can follow through on commitments that are not time consistent. The experience with inflation targeting - another policy that is not time consistent (Barro and Gordon 1983)—suggests that central banks can keep certain commitments, but the degree to which such successes imply that commitment strategies of the type we consider are feasible is uncertain.

We do not directly consider the potential for negative interest rates or quantitative easing $(\mathrm{QE})$ aimed at lowering long-term interest rates. Our reading of related work suggests that these policies would provide a stimulus to economic activity and hence are among plausible tools to combat the deterioration in economic performance from an ELB. Nonetheless, the literature also suggests that such policies may have limits-in either potential scope or efficacy - and that a focus on traditional approaches and commitment strategies is useful. As former Federal Reserve chairman Ben Bernanke (2015a, p. 529) notes in his memoir, "Our unconventional policy tools, such as quantitative easing, involved costs and risks as well as benefits. It made sense to use unconventional tools less aggressively than more conventional tools like interest rate cuts." Notably, the size of QE needed to achieve even modest improvements in macroeconomic outcomes is very large. Reifschneider (2016) provides illustrative simulations in which policymakers confronted by a severe U.S. recession act to combat the economic downturn by augmenting a conventional response (akin to the simple rule 
we consider) through a combination of forward guidance and QE. These simulations suggest roles for both forward guidance-which we analyze in our discussion of commitments-and QE. Reifschneider's (2016) simulations suggest that even in the case where the total increase in the central bank's balance sheet owing to QE equals $\$ 4$ trillion, the stabilization gain is small relative to the size of the recession. Moreover, these moderate benefits arise in the FRB/US model, where the effects of QE are large relative to those in some DSGE models. Finally, the efficacy of QE as a regular component of a central bank's policy tool kit depends both on the effects of increasing balance sheets (as for Reifschneider 2016) and on the strategy for unwinding the balance sheet, as repeated doses of QE absent unwinding would lead to an ever-increasing balance sheet. Nonetheless, a more thorough set of simulations across a broad range of conditions, as in the stochastic simulation approach we adopt in our analysis of interest rate strategies, is required for an assessment of QE's ability to improve performance, and remains an important topic for future research. ${ }^{4}$

\section{Previous Contributions, and How Our Analysis Differs}

The potential for the ELB to bind and impede economic performance, as well as policy strategies to ameliorate such effects, has been analyzed extensively since concerns regarding its effects were raised by Larry Summers (1991). Before the Great Recession, research suggested that ELB episodes would be infrequent, would have modest effects on economic performance, and could be mitigated by appropriate strategies. For example, Athanasios Orphanides and Volker Wieland (1998), Reifschneider and Williams (2000), and Günter Coenen, Orphanides, and Wieland (2004) consider the effects of the ELB in structural and semistructural models, including the FRB/US model. The results of Reifschneider and Williams (2000) are illustrative of those in this literature: These authors estimated that an ELB of zero would bind less than 15 percent of the time and that such episodes would average less than one and a half years under the Taylor (1993) rule if the equilibrium short-term nominal interest rate $r^{*}$ were equal

4. Kiley (2014) reviews related work up to that point and provides estimates of a small DSGE model in which the estimated effect of a flattening in the yield curve (as in QE) on economic activity is much smaller than the effect of a decline at both the short and long ends of the yield curve (conditional on the same-sized decline in yields at the long end). 
to 3 percent. ${ }^{5}$ In contrast, our simulations suggest that the ELB will bind about 40 percent of the time and will last, on average, two and a half years under such conditions (with the distribution of the length of ELB episodes strongly skewed to the upside, implying a high probability of episodes of substantially longer duration). That said, our analysis using the FRB/US model builds closely on the work of Reifschneider and Williams (2000), and our emphasis on the need for a risk adjustment to simple policy rules and commitments to make up forgone accommodation after an ELB episode draws directly on their insights.

The New Keynesian literature explores similar issues in more stylized models (Wolman 1998; Eggertsson and Woodford 2003; Adam and Billi 2006) — with Gauti Eggertsson and Michael Woodford (2003) emphasizing how changes in the policy strategy, involving commitments akin to price level targeting, can substantially mitigate these already modest effects of the ELB. Summarizing this range of precrisis work, Michael Kiley, Eileen Mauskopf, and David Wilcox (2007) — in a memo sent to the Federal Open Market Committee (FOMC) in 2007, 2009, and 2010—characterized the literature as suggesting that the risks from the ELB to macroeconomic stability were "de minimis."

Williams (2009) revisits many of the same issues as Reifschneider and Williams (2000), again using the FRB/US model. ${ }^{6}$ Despite drawing shocks from only the more volatile 1968-83 period, the incidence of the ELB estimated by Williams (2009) for a steady-state nominal interest rate of 3 percent is only 16 percent, whereas we estimate that ELB episodes are likely to be substantially more frequent under traditional policy rules, occurring nearly 40 percent of the time. (Below, at the end of section III, we discuss the factors that led to a more binding ELB in our analysis, including the removal of a mechanism that implied extraordinary accommodation relative to a simple rule following an ELB period and the maximum assumed duration of ELB episodes.)

5. These earlier studies reached these conclusions, in part, because the models used implied a fairly stable economy: For example, the models of Orphanides and Wieland (1998) and Coenen, Orphanides, and Wieland (2004) implied that the standard deviation of the output gap would equal about 1 percent absent an ELB. In contrast, the Congressional Budget Office's output gap has a standard deviation closer to $2 \frac{1}{2}$ percent. In the models we consider, economic activity is fundamentally more volatile than in these earlier assessments.

6. Chung and others (2012) focus on developments following the Great Recession and suggest that macroeconomic models, including FRB/US and standard DSGE models, may understate ELB risks. However, their analysis does not consider the possible frequency of ELB episodes in the future. 
Despite the significantly larger constraint implied by the ELB in our analysis, the broad message regarding how to ameliorate these effects in our work is similar to that of Reifschneider and Williams (2000) and Williams (2009): When the equilibrium real interest rate is low, a sizable risk adjustment to traditional rules on the order of $1 / 2$ to 1 percentage point is required to achieve an inflation target of 2 percent; such an adjustment implies that inflation must average closer to 3 percent outside ELB periods. In addition, policies that accumulate the forgone accommodation induced by the ELB and provide that accommodation after the conditions generating an ELB episode mitigate the ELB's most severe adverse effects. A key contribution of our work is to show that these features are more important than previous work suggested, because the ELB may bind more frequently. And we also demonstrate that these approaches behave similarly in both the FRB/US and DSGE models.

We apply the same type of analysis that we conduct with FRB/US to our DSGE model. This approach departs from that in most DSGE work. The analyses in DSGE models have often not employed the quantitative approach used herein and have focused more on illustrative cases using impulse response analysis and steady-state comparisons (Wolman 1998; Eggertsson and Woodford 2003). The general result from these investigations and related work is that New Keynesian models imply that steadystate inflation is very costly because of its effects on price dispersion, and commitment strategies are very effective at ameliorating the ELB's adverse effects. As a result, the optimal level of inflation is typically quite low in this literature, and the ELB is not a large problem under appropriate monetary policy strategies (Schmitt-Grohé and Uribe 2010). An analysis using DSGE models that is closer in spirit to ours is that of Coibion, Gorodnichenko, and Wieland (2012), who revisit the optimal inflation rate in the context of a DSGE model using the welfare function implied by their DSGE model. They conclude, using a model calibrated to capture features of the data spanning the years 1947 to 2011, that the optimal rate of inflation in their preferred specification is about $1 \frac{1}{2}$ percent, not far from the 2 percent target of the Federal Reserve and many other central banks. It is particularly important that they assume an equilibrium real federal funds rate of 2 percent in their baseline case, far above recent estimates. Moreover, the costs of inflation are tightly linked to their model of price adjustment, which implies that price dispersion rises materially as inflation increases. Finally, their baseline case uses an approach in which policymakers commit to keep track of forgone accommodation and make up some of this accommodation after the conditions generating the ELB end; such commitments are well known to generate 
good performance in DSGE models, and we emphasize both this commitment case and outcomes under traditional rules of the Taylor (1993) form.

\section{Our Approach}

Relative to earlier research, our analysis builds on the recent literature emphasizing the possibility that the equilibrium real interest rate will remain persistently below earlier norms and compares results from two empirical models of the U.S. economy.

\section{II.A. Estimates of the Equilibrium Real Interest Rate}

Looking back over the past 50 years, there appears to be a trend decline in the real interest rate (Hamilton and others 2015). Laubach and Williams (2003) present a semistructural model that attempts to extract the longrun value of the short-term policy interest rate from a model with an IS curve and a Phillips curve. Extending this analysis through more recent data (Laubach and Williams 2016; Holston, Laubach, and Williams 2017), estimates of the likely long-run value of the short-term nominal interest rate - the equilibrium real interest rate, $r^{*}$ — have fallen to quite low levels.? Del Negro and others (2017) review related literature and present estimates from both time series approaches and structural models.

Although the economic forces behind a possible decline in $r^{*}$ are outside the scope of our analysis, a number of factors may be at play. A slower pace of potential output growth may depress $r^{*}$ by altering the balance between investment in productive capacity and savings. Demographic shifts—both slower population growth and changes in age composition-may add to such trends (Gagnon, Johanssen, and Lopez-Salido 2016). Another strand of the literature emphasizes shifts in the demand for safe and liquid assets; for example, Bernanke (2005) pointed to a "global saving glut," combined with strong demand for U.S. assets, as putting downward pressure on yields for safe U.S. securities. Del Negro and others (2017) review an array of factors that suggest changes in the safety and liquidity premium (or convenience yield) contribute to the low level of interest rates.

In terms of magnitudes, most estimates suggest that $r^{*}$ is likely to remain considerably lower than the $2 \frac{1}{2}$ percent average for the real interest rate experienced during the 1960-2007 period. Figure 3 presents the evolution of the real federal funds rate since 1960, along with the estimates of

7. It is, however, worth bearing in mind that some research has highlighted that the data are not strongly informative about the decline (Kiley 2015). 
Figure 3. The Real Federal Funds Rate and Estimates of $r^{*}, 1965-2016$

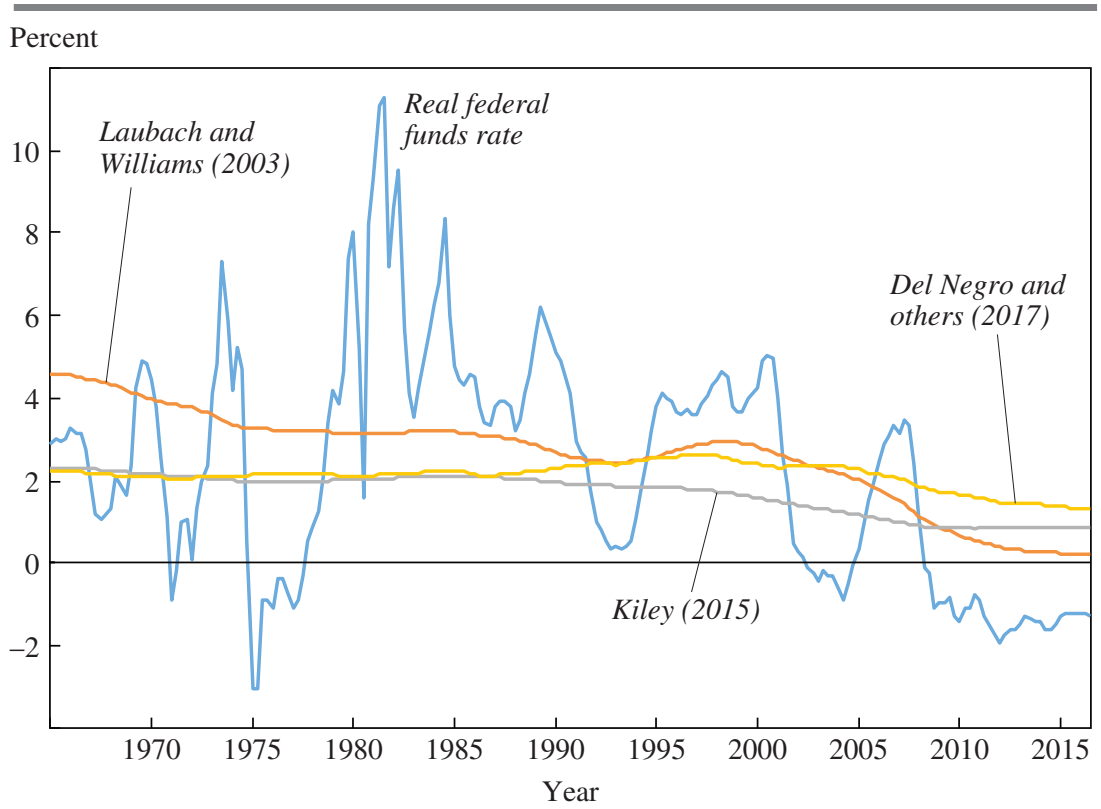

Sources: Federal Reserve Board; Del Negro and others (2017); Kiley (2015); Laubach and Williams (2003).

$r^{*}$ from the models of Laubach and Williams (2003), Kiley (2015), and Del Negro and others (2017). According to Laubach and Williams's (2003) model, $r^{*}$ exceeded 3 percent from the 1960s through the 1980s, and it may have been as low as 0 percent in the 2010s; in contrast, Kiley's (2015) and Del Negro and others' (2017) models point to a somewhat higher value recently, of about 1 percent; and both studies point to smaller shifts in $r^{*}$ over time than Laubach and Williams's (2003) model. Much of our analysis emphasizes the higher value of 1 percent-and any effects of the ELB that we identify would be larger if $r^{*}$ were closer to zero.

\section{II.B. Alternative Macroeconomic Models}

Our analysis uses two models of the U.S. economy: the DSGE model of Lindé, Smets, and Wouters (2016); and the Federal Reserve Board's FRB/US model.

The DSGE model follows in the tradition associated with Smets and Wouters (2007), and now employed at many central banks: It is based on optimizing behavior by representative households and firms; it is tied to the New Keynesian literature in emphasizing staggered nominal price and 
wage setting as key frictions governing the trade-off between activity and inflation stabilization and the effects of monetary policy; and it is estimated as a system using Bayesian methods. ${ }^{8}$ Relative to earlier models, a key advantage of Lindé, Smets, and Wouters's (2016) model is that it was developed after the Great Recession to incorporate the outsized movements in economic activity witnessed during that period and to consider the length and effects of ELB episodes. ${ }^{9}$

As emphasized by Brayton, Laubach, and Reifschneider (2014), the FRB/US model of the U.S. economy is one of several that Federal Reserve Board staff members consult for forecasting and the analysis of macroeconomic issues, including both monetary and fiscal policy. The model is large relative to DSGE models, and its equations are linked to core macroeconomic frameworks, such as the permanent income model of consumption and the neoclassical user cost model of investment, but are not closely tied to representative agent optimization problems, as in DSGE models. It is particularly important that the FRB/US model includes inertial behavior in many of its spending equations, as well as its price and wage equationsthrough the inclusion of adjustments costs that introduce a longer lag structure into the dynamic specification of the model than in smaller DSGE models. In addition, a number of key frictions are incorporated in the empirical specification, including a role for liquidity-constrained households, and disaggregated equations for firms' investments in durable equipment, intellectual property, and nonresidential structures that include ad hoc accelerator terms that may capture the effects of sales on liquidity-constrained firms' ability to invest. Finally, a variety of interest rates-including yields on Treasury securities, corporate bond yields, and residential mortgage rates-are determined as the expected average value of the federal funds rate over the appropriate holding period plus endogenous term and risk premiums; equity prices equal the present discounted value of corporate earnings based on an estimated required return to equity; and monetary

8. Examples of such models in use at central banks include the EDO and SIGMA models at the Federal Reserve Board (Chung, Kiley, and Laforte 2010; Erceg, Guerrieri, and Gust 2005) and the New Area-Wide Model at the European Central Bank (Christoffel, Coenen, and Warne 2008).

9. Earlier contributions, such as Edge, Kiley, and Laforte (2008), focused on the period after the early 1980s and before the Great Recession, yielding models that predict relatively modest cyclical fluctuations - a potential problem we earlier identified with contributions to the ELB debate, such as those by Orphanides and Wieland (1998), Reifschneider and Williams (2000), and Coenen, Orphanides, and Wieland (2004). 
Figure 4. Impulse Response to a Contemporaneous Monetary Policy Shock

FRB/US
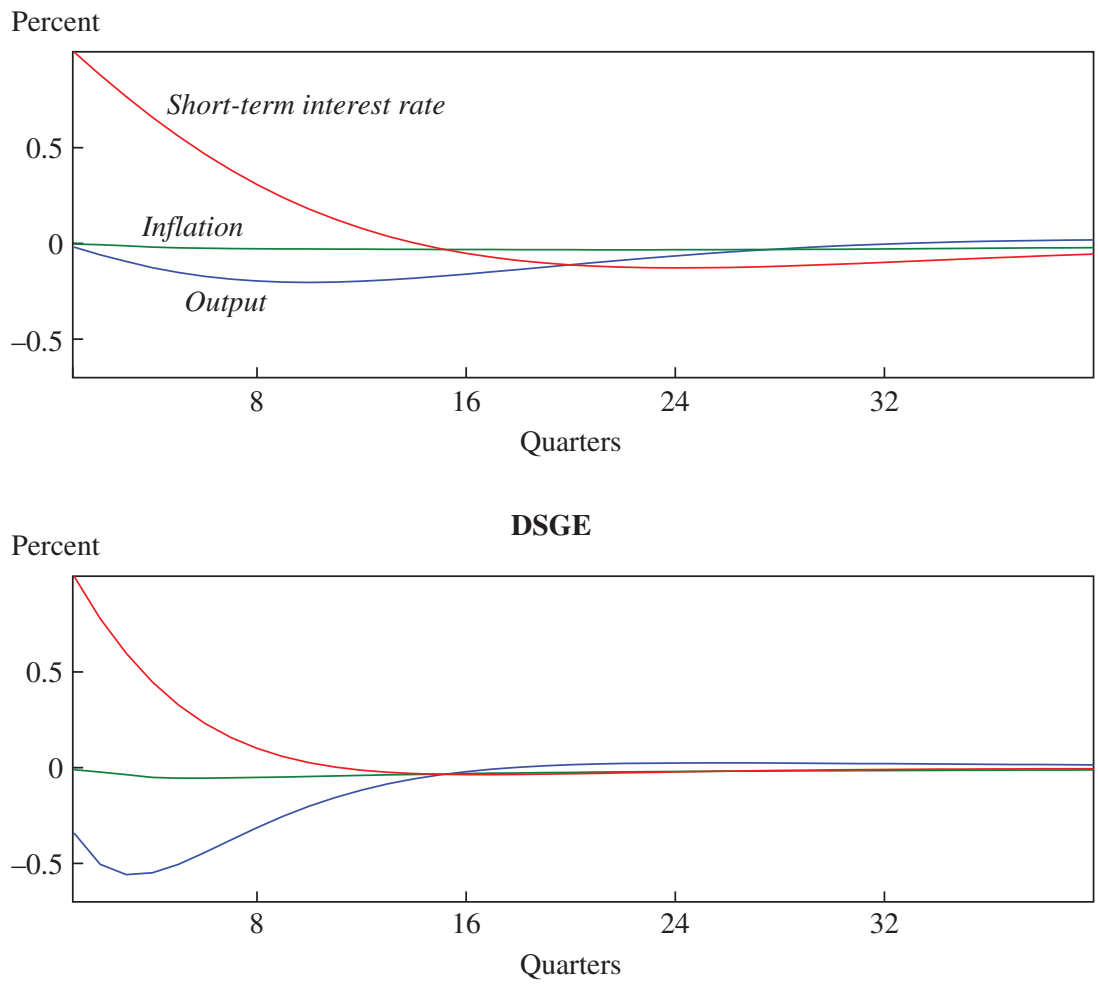

Sources: Federal Reserve Board; Lindé, Smets, and Wouters (2016); authors' calculations.

policy is modeled as a simple rule for the federal funds rate subject to the zero lower bound on nominal interest rates.

To illustrate the properties of both the DSGE and FRB/US models that are important when examining the effects of the ELB, we consider the effects of alternative monetary policy actions. Figure 4 presents the response of each model to a shock to the monetary policy rule of 100 basis points. In each case, inflation responds very little, as both models feature fairly flat Phillips curves. Output falls modestly. The decline is somewhat larger and more immediate in the DSGE model, with the maximum decline in output slightly exceeding $1 / 2$ percent. Although the differences across models are noticeable, the more prominent takeaway from these responses is the relative similarity of the models. 
Figure 5. Impulse Response to a Monetary Policy Shock 12 Quarters in the Future

FRB/US

\section{Percent}
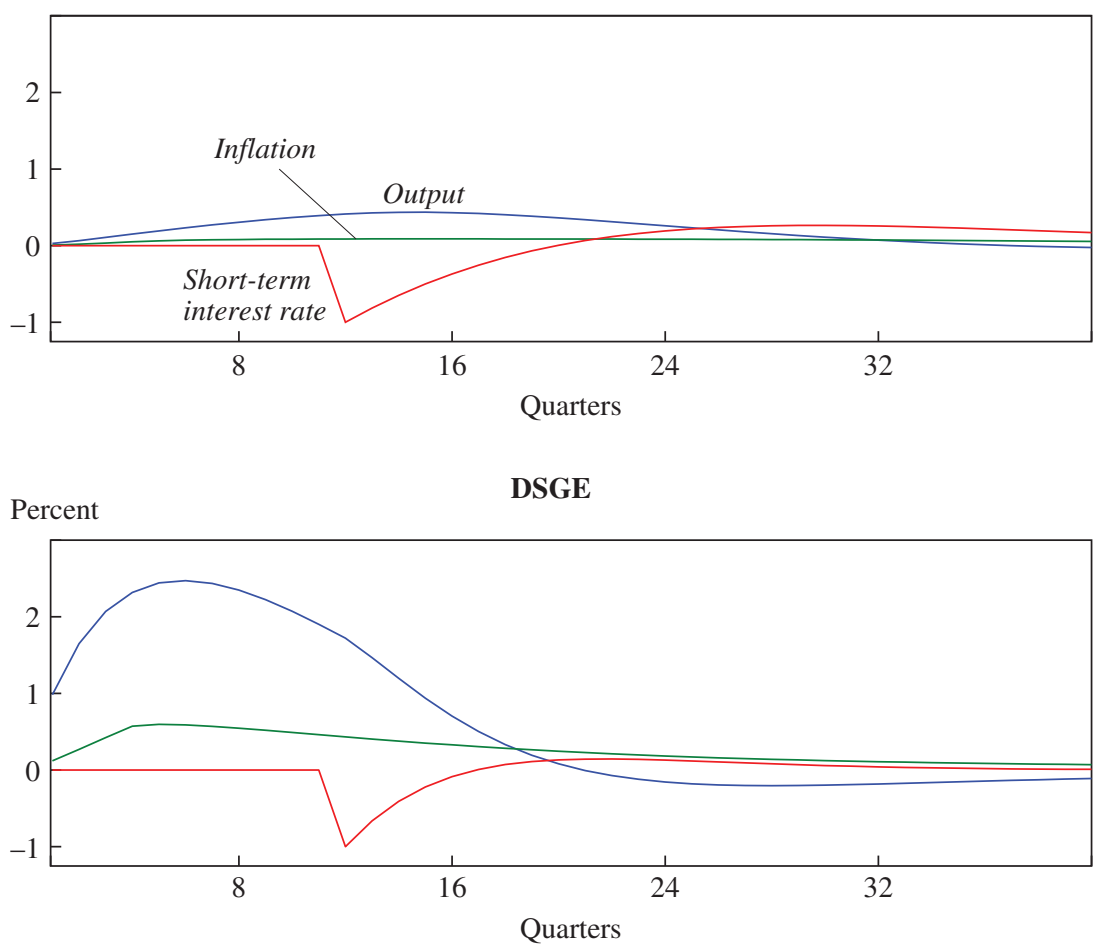

Sources: Federal Reserve Board; Lindé, Smets, and Wouters (2016); authors' calculations.

Figure 5 illustrates the relative power of forward guidance in each model. It considers a decline in the policy interest rate of 100 basis points 12 quarters in the future, holding the nominal interest rate fixed at baseline before the 12th quarter and thereafter reverting to the policy rule. The power of forward guidance in DSGE models has been highlighted by a number of scholars, including Hess Chung, Edward Herbst, and Kiley (2015); Alisdair McKay, Emi Nakamura, and Jón Steinsson (2016); and Kiley (2016). The scale in the figure is held constant across the FRB/US and DSGE results to highlight the differences in the results. As is clear from the bottom panel in figure 5, forward guidance is very powerful in the DSGE model, with output rising nearly $2 \frac{1}{2}$ percent in response to the shock. In contrast, the power of forward guidance is much more limited in the FRB/US simulation. 
Figure 6. Amplification of Recessionary Shocks by the Effective Lower Bound

FRB/US

Percent
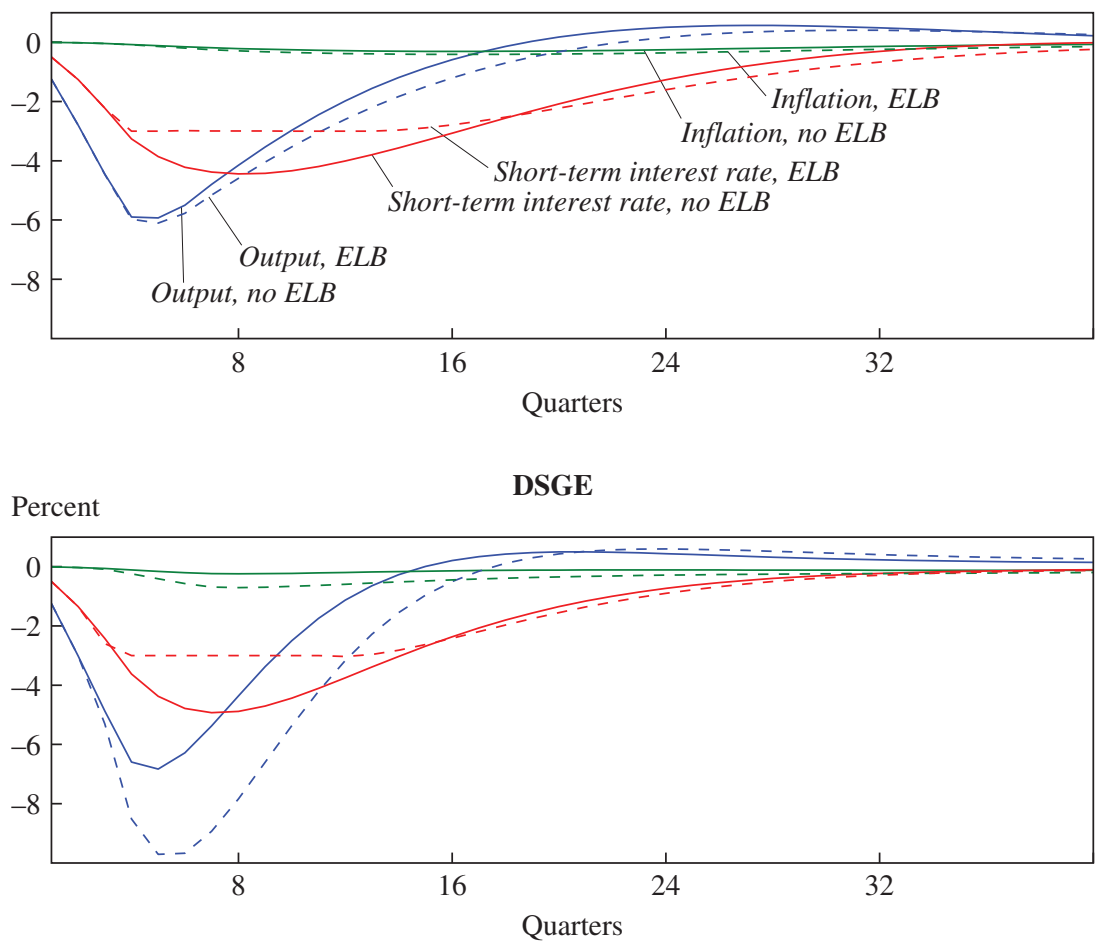

Sources: Federal Reserve Board; Lindé, Smets, and Wouters (2016); authors' calculations.

These results suggest that the DSGE and FRB/US models differ in important ways along this dimension.

The force of forward guidance in the DSGE model points to the possibility that monetary policy may be more effective in mitigating any adverse effects of an ELB on economic performance. However, it is also important to keep in mind that the power of forward guidance is simply an illustration of the amplification of shocks in the DSGE model absent the cushioning effect on output and inflation that comes from monetary policy adjustments. To see this, figure 6 shows the effects of a severe shock to aggregate demand in the DSGE and FRB/US models. In the DSGE model, the downturn is caused by an exogenous sequence of shocks to the model's risk premium shock, and the FRB/US results reflect an exogenous sequence of 
negative shocks to the consumption equation. The top and bottom panels show FRB/US and DSGE results, respectively, with the solid lines illustrating the effects in the absence of the ELB and the dashed lines illustrating outcomes in the presence of an ELB 3 percentage points below steady state- that is, assuming a steady-state nominal interest rate of 3 percent. In both panels, when not constrained, the federal funds rate is set according to the estimated policy rule. As can be seen, the ELB greatly magnifies the consequences of the shock in the DSGE model, with the trough value of the output gap declining from about 7 percent in the absence of the ELB to nearly 10 percent in the presence of the ELB. In the constrained case, the federal funds rate is at its effective lower bound for about three years. Although the ELB binds for a similar period in the FRB/US simulation, amplification of the recession by the ELB is modest.

\section{II.C. Our Simulation Approach}

Much of the remainder of our analysis involves computation of moments from simulations of the models. In computing these simulations:

-We generate 500 simulated samples of 200 periods (that is, 50 years), initializing the simulations at the models' nonstochastic steady state. The first 100 periods of a simulated sample are deleted when we compute summary statistics to minimize the effects of initial conditions.

-We impose the ELB appropriately under alternative assumptions about the steady-state nominal interest rate. For example, we most often consider steady-state nominal interest rates of 5, 4, or 3 percent, which would be consistent with a 2 percent inflation target and $r^{*}$ equal to 3 percent, which would be consistent with estimates from Laubach and Williams's (2003) model through 2000; 2 percent, a common pre-crisis value; or 1 percent, approximately the most recent estimated value from the models of Kiley (2014) and Del Negro and others (2017).

-We draw shocks from the period 1970 to 2015 for FRB/US (via a bootstrap of the residuals from the model) and from the estimated variance-covariance matrix of shocks for the DSGE model. In each case, we assume no shocks to monetary policy; that is, monetary policy strictly follows the rules we posit below.

-Our algorithm imposes the ELB in a manner similar to that of Williams (2009) and Luca Guerrieri and Matteo Iacoviello (2015). We assume that agents never expect the ELB to bind for more than 15 years. In contrast, Williams (2009) assumes that the ELB only strictly binds (in expectation) for up to 4 years. 
-We include an emergency fiscal stimulus package that is enacted when the output gap is lower than -10 percent. This fiscal package is implemented as an expansion of government purchases, and prevents the emergence of extremely adverse outcomes. A similar approach is followed by Reifschneider and Williams (2000) and Williams (2009). In the FRB/US model, the fiscal stimulus package is rarely invoked, and results would largely be the same without this assumption. The fiscal stimulus package is more important in the DSGE model, particularly for some monetary policy strategies that fail to counteract the effects of the ELB effectively. This importance is consistent with the property of this model highlighted above: Once the ELB binds in the DSGE model, amplification of shocks can become large, and this can necessitate extraordinary measures to rescue the economy. Although the specific quantitative results we present for the DSGE model depend on the nature of the fiscal package, the policy lessons do not.

-For both the FRB/US and DSGE models, we assume that agents have model-consistent expectations. As a consequence, households and firms fully understand the policy regime that is in place. Thus, our analysis is helpful for assessing how the economy would behave once the policy regime has been in place for some time. Our analysis may not be as useful for an assessment of how the economy might behave in the immediate aftermath of the announcement or adoption of such a policy. Understanding the steady-state benefits are clearly of first-order importance in assessing whether to adopt any particular policy; if the steady-state behavior is not desirable, then it is clearly not worthwhile to assess the transition. For a detailed discussion of transition issues using the FRB/US model, see Reifschneider and Roberts (2006). ${ }^{10}$

An important element of the stochastic simulations we perform is that they admit the possibility of back-to-back recessions-as the United States indeed experienced in the early 1980s. There is no requirement that the economy will have fully recovered from one recessionary episode before additional adverse shocks arrive, as in the more illustrative simulation approaches of Eggertsson and Woodford (2003), Reifschneider and Roberts (2006), and Reifschneider (2016). Rather, the shocks are

10. Reifschneider and Roberts (2006) examine the ability of rules similar to the ones we explore here to mitigate the effects of the ELB using the FRB/US model. A key feature of their analysis is the consideration of the rules under both fully model-consistent expectations and assuming that only financial market participants have model-consistent expectations, while other agents form expectations using the FRB/US model's option of vector autoregressive-based expectations. The use of vector autoregressive-based expectations effectively means that agents form expectations assuming the historical policy regime remains in place. 
Table 1. Standard Deviations of the Output Gap, Core Inflation, and Federal Funds Rate

\begin{tabular}{lccc}
\hline Period or model & Output gap & Core inflation & Nominal federal funds rate \\
\hline 1960-2007 & 2.3 & 2.2 & 3.3 \\
1984-2007 & 1.4 & 1.0 & 2.4 \\
FRB/US & 2.2 & 1.5 & 2.8 \\
DSGE & 2.4 & 2.4 & 2.6 \\
& & Frequency of ELB in model simulations \\
FRB/US & & 2.0 percent \\
DSGE & & 1.1 percent \\
\hline
\end{tabular}

Sources: Federal Reserve Board; Lindé, Smets, and Wouters (2016); authors' calculations.

a. The FRB/US and DSGE models are estimated under the rule in equation 1 with a steady-state nominal interest rate of 6 percent.

simply drawn from the unconditional distribution. To the extent that our models, including their shocks, are realistic, this approach will give the simulations a reasonable chance of encountering challenging situations and thus "testing the mettle" of the various policy strategies. This advantage is important for assessing likely behavior across the business cycle and over time.

\section{Economic Performance under Traditional Approaches}

This section assesses economic performance under traditional policy rules, including an estimated rule and a simple rule similar to that introduced by Taylor (1993). We then compare our results with others in the literature.

\section{III.A. Performance from 1960 to 2007}

Our analysis begins with the properties of the DSGE model and the FRB/US model under an estimated policy rule. Table 1 presents historical statistics for the output gap (as measured by 100 times the natural log of real GDP divided by the Congressional Budget Office's estimate of potential), core PCE inflation (measured on a four-quarter basis), and the nominal federal funds rate-along with statistics from stochastic simulations of the DSGE model and the FRB/US model assuming that the steady-state nominal interest rate equals 6 percent (the 1960-2007 average) and the effective lower bound is zero. In each model, the federal funds rate is set according to the rule

$$
i(t)=0.9 i(t-1)+0.2 \pi_{4}(t)+0.15 y(t)+0.25 \Delta y(t),
$$


where $i$ is the nominal interest rate (measured at an annual rate), $y$ is the output gap, and $\pi_{4}$ is the four-quarter change in the natural log of core PCE prices (throughout, we use quarterly data). This rule was estimated for the 1988-2007 period using data from the Congressional Budget Office on the output gap; constants are suppressed in the expression of the rule.

As can be seen by comparing the standard deviations of output, inflation, and the nominal federal funds rate from the DSGE model with the estimates based on data from 1960 to 2007, the DSGE model replicates the sample moments very closely, which is unsurprising, given that the estimation sample for this model corresponds, roughly, to this period. The exception is the nominal federal funds rate, where the standard deviation from model simulations is less than the sample standard deviation during the entire 1960-2007 period and lies closer to the value seen during the years 1984-2007; this may reflect the fact that the model simulations assume no exogenous disturbances to the policy rule, and such systematic behavior of monetary policy may be a better characterization of monetary policy actions since the disinflation experienced under Federal Reserve chairman Paul Volcker in the early 1980s. The statistics from the FRB/US model are also broadly similar to their sample counterparts-although inflation is slightly less volatile (with a standard deviation of 1.5 percentage points, whereas the sample counterpart from 1960-2007 equals 2.2 percentage points). The ELB rarely binds in either model for a steady-state nominal interest rate of 6 percent.

\section{III.B. Economic Performance under Lower Steady-State Nominal Interest Rates}

We now consider the implications of a lower steady-state nominal interest rate for economic performance in the models we consider. Our analysis begins with performance under each model's estimated policy rule and then turns to behavior under a simple Taylor (1993) policy rule, under the parameter values suggested by, for example, Federal Reserve chair Janet Yellen (2017). These rules are useful benchmarks because they are simple ways to capture the behavior of inflation-targeting central banks. In all cases, we assume that the inflation target is 2 percent and the equilibrium real interest rate, $r^{*}$, is between 1 and 3 percent, as is consistent with the evidence reviewed above. As a result, our discussion focuses on the steadystate nominal interest rates ranging from 3 to 5 percent. Although outside the main focus of our analysis, we also consider higher and lower values of the steady-state nominal interest rate in some cases, to compare with 
Table 2. Performance under Estimated Rule in Alternative Models and for Alternative Values of the Steady-State Nominal Interest Rate

\begin{tabular}{lcccccc}
\hline $\begin{array}{l}\text { Nominal } \\
\text { interest } \\
\text { rate }\end{array}$ & $\begin{array}{c}\text { ELB } \\
\text { frequency } \\
\text { (percent) }\end{array}$ & $\begin{array}{c}\text { Mearation } \\
\text { of ELB } \\
\text { (quarters) }\end{array}$ & $\begin{array}{c}\text { Mean } \\
\text { output } \\
\text { gap }\end{array}$ & $\begin{array}{c}\text { Mean } \\
\text { inflation rate } \\
\text { (target }=2.0)\end{array}$ & $\begin{array}{c}\text { Root mean } \\
\text { square } \\
\text { deviation of } \\
\text { output gap }\end{array}$ & $\begin{array}{c}\text { Root mean } \\
\text { square } \\
\text { deviation } \\
\text { of inflation } \\
\text { rate }\end{array}$ \\
\hline $\begin{array}{l}\text { DSGE } \\
5 \text { percent }\end{array}$ & 3.2 & 5.1 & -0.1 & 2.0 & 2.5 & 2.5 \\
4 percent & 7.8 & 6.5 & -0.4 & 1.7 & 3.4 & 3.0 \\
3 percent & 17.4 & 8.8 & -1.3 & 0.9 & 5.7 & 4.6 \\
FRB/US & & & & & & \\
5 percent & 5.1 & 5.8 & -0.1 & 1.9 & 2.4 & 1.5 \\
4 percent & 12.8 & 8.3 & -0.4 & 1.7 & 2.7 & 1.7 \\
3 percent & 31.7 & 9.2 & -1.3 & 1.2 & 3.7 & 2.1 \\
\hline
\end{tabular}

Sources: Federal Reserve Board; Lindé, Smets, and Wouters (2016); authors' calculations.

the historical average nominal interest rate of 6 percent or to consider the implications of an $r^{*}$ as low as 0 percent, as in the estimates from Laubach and Williams's (2003) model presented in figure 2.

PERFORMANCE UNDER THE ESTIMATED RULE Table 2 presents stochastic simulations of each model for alternative values of the steady-state nominal interest rate under the estimated rule, incorporating the ELB. In the DSGE model, there is some modest deterioration in macroeconomic performance owing to the ELB for a steady-state nominal interest rate of 4 percent. For a steady-state nominal interest rate of 3 percent (or lower), the impact on economic performance is more sizable; inflation systematically falls short of the target, averaging less than 1 percent, and output is below potential, on average. Note that these adverse effects arise even though the ELB is binding only 17 percent of the time.

Significant effects of the ELB also arise in the FRB/US model. As shown in the first row of the bottom panel of table 2, the effects of the ELB are modest for a steady-state nominal interest rate of 5 percent: The ELB is expected to bind about 5 percent of the time, and output and inflation volatility are little different from the case shown in table 1. Economic performance is worse for a steady-state nominal interest rate of 4 percent, with inflation falling $1 / 4$ percentage point below target and output averaging nearly $1 / 2$ percent below potential. As with the DSGE model, for steady-state nominal interest rates of 3 percent, performance deteriorates sharply, with inflation falling substantially short of the target (with an average across 
simulations of 1.2 percent) and output averaging more than 1 percent below potential. The ELB binds about one-third of the time.

Previous research points to one main reason for the poor performance of the estimated rule in the models we consider, which is that the rule includes a sizable response to the change in the output gap, and such a response implies that accommodation is removed as soon as a recovery begins (rather than waiting until the level of activity has recovered) - a response that short-circuits a recovery, as emphasized by Roberto Billi (2011).

A SIMPLE RULE An alternative to the estimated rules is a rule in the simpler class suggested by Taylor $(1993,1999)$, whereby the nominal interest rate only responds to inflation and the output gap. Such a rule has a number of desirable features for our analysis: It relates the current level of the nominal interest rate to the deviations of inflation from target and output from potential, and therefore captures both goals of a dual-mandate central bank; it has been shown to produce reasonable economic performance abstracting from the ELB (Taylor and Williams 2010); and it is a benchmark often consulted within the Federal Reserve, including through regular presentations in the discussion of monetary policy alternatives in material produced for the FOMC and as represented by calculators available at Federal Reserve Banks. ${ }^{11}$

Table 3 presents statistics for the version of the rule under a 2 percent inflation target,

$$
i(t)=r^{*}+2+1.5\left[\pi_{4}(t)-2\right]+y(t) .
$$

Overall, the results suggest that this policy rule is as ineffective at addressing the challenges that arise if the steady-state nominal interest rate lies below 4 percent as the estimated policy rule. In the FRB/US model, inflation and output systematically fall short of their objectives to a degree similar to that under the estimated rule when the steady-state nominal interest rate equals 3 percent. Moreover, the ELB binds nearly two-fifths of the time, and the

11. Materials prepared by staff members of the FOMC began regularly reporting the prescriptions from this rule in advance of decisions in January 2004, and they have continued to report these prescriptions through the most recent publicly available materials (in the Bluebook and more recently the Tealbook B; see https://www.federalreserve.gov/ monetarypolicy/fomchistorical2004.htm). The Taylor rule utility at the Federal Reserve Bank of Atlanta can be found at https://www.frbatlanta.org/cqer/research/taylor-rule.aspx; the Taylor rule utility at the Federal Reserve Bank of Cleveland can be found at https://www. clevelandfed.org/en/our-research/indicators-and-data/simple-monetary-policy-rules/about.aspx. 
Table 3. Performance under Simple Rule in Alternative Models and for Alternative Values of the Steady-State Nominal Interest Rate

\begin{tabular}{lcccccc}
\hline $\begin{array}{l}\text { Nominal } \\
\text { interest } \\
\text { rate }\end{array}$ & $\begin{array}{c}\text { ELB } \\
\text { frequency } \\
\text { (percent) }\end{array}$ & $\begin{array}{c}\text { Muration } \\
\text { of ELB } \\
\text { (quarters) }\end{array}$ & $\begin{array}{c}\text { Mean } \\
\text { output } \\
\text { gap }\end{array}$ & $\begin{array}{c}\text { Mean } \\
\text { inflation rate } \\
\text { (target }=2.0)\end{array}$ & $\begin{array}{c}\text { Root mean } \\
\text { square } \\
\text { deviation of } \\
\text { output gap }\end{array}$ & $\begin{array}{c}\text { Root mean } \\
\text { square } \\
\text { deviation } \\
\text { of inflation } \\
\text { rate }\end{array}$ \\
\hline DSGE & & & & & & \\
6 percent & 0.0 & n.a. & 0.0 & 2.0 & 2.3 & 3.0 \\
5 percent & 12.9 & 7.4 & -0.5 & 1.7 & 3.7 & 3.8 \\
4 percent & 21.1 & 8.9 & -1.2 & 1.0 & 5.4 & 4.8 \\
3 percent & 32.6 & 12.0 & -2.3 & 0.1 & 7.3 & 6.1 \\
FRB/US & & & & & & \\
6 percent & 5.3 & 4.5 & -0.1 & 2.0 & 2.3 & 1.6 \\
5 percent & 10.0 & 5.5 & -0.1 & 1.9 & 2.4 & 1.6 \\
4 percent & 20.2 & 7.8 & -0.4 & 1.7 & 2.8 & 1.8 \\
3 percent & 38.3 & 9.8 & -1.1 & 1.2 & 3.4 & 2.2 \\
\hline
\end{tabular}

Sources: Federal Reserve Board; Lindé, Smets, and Wouters (2016); authors' calculations.

mean duration of ELB episodes is two and a half years (and the duration of episodes is highly positively skewed, implying that some episodes are much longer). In the DSGE model, the deterioration in performance under a simple Taylor rule is worse than under the estimated rule, with inflation averaging about 0 percent when the steady-state nominal interest rate equals 3 percent. More generally, the simple rule performs relatively poorly even at much higher steady-state interest rates, suggesting that the simple rule is far from optimal in this model. ${ }^{12}$ This poor performance relative to the estimated rule arises because the inertia in the estimated rule has a significant stabilizing effect away from the ELB in the DSGE model: The path of interest rates is very important in this class of models, as suggested by the forward guidance simulations presented above, and the persistence in the path for the nominal interest rate induced by the presence of the lagged interest rate in the estimated policy rule stabilizes inflation and activity away from the ELB in the DSGE model; the Taylor rule does not have this feature, and output and especially

12. This feature is not unique to the DSGE model. For example, Williams (2003) shows that simple rules of this type are far from optimal in the FRB/US model. 
inflation are more volatile as a result (as can be seen in the row for a steady-state nominal interest rate of 5 percent)—which leads to a more binding ELB, with larger adverse effects, in the DSGE model under the Taylor (1993) rule. This result echoes that of Coibion, Gorodnichenko, and Wieland (2012).

Given the changes in the mean and standard deviations of inflation under alternative values of the steady-state nominal interest rate, it is instructive to examine the entire distribution of outcomes from the simulations in each model. Figure 7 presents the probability density functions (PDFs) and cumulative distribution functions (CDFs) for output, inflation, and the nominal federal funds rate for an inflation target of 2 percent and equilibrium real interest rates from 0 to 4 percent. When the steady-state nominal interest rate equals 6 percent, as was the case during the 1960-2007 period, simulated outcomes for inflation and output are symmetric around their target values. But lower values of the steady-state nominal interest rate, in interaction with the ELB, induce notable asymmetries in outcomes: Output averages below potential and inflation averages below target because their downside tails are larger than their upside tails. This asymmetry is important to keep in mind when thinking both about policy strategies and about the implications for economic welfare, as the costs of above- or belowtarget inflation and output may be asymmetric.

\section{III.C. Comparisons with Earlier Analyses}

The frequency with which the ELB binds and the magnitude of the adverse effects on economic performance may be surprising in light of the earlier literature. In particular, Reifschneider and Williams (2001) and Williams (2009) find that the ELB will bind less than one-fifth of the time for an equilibrium real interest rate of 1 percent and an inflation target of 2 percent, and do not find the sizable negative skewness in economic activity reported above using the FRB/US model. Similarly, Coibion, Gorodnichenko, and Wieland (2012) report important effects of the ELB, but the impression from their discussion is that the ELB is not an extraordinary impediment to economic performance, at least in the DSGE model they consider. Other DSGE analyses (Schmitt-Grohé and Uribe 2011) leave a similar impression.

An obvious candidate explanation is changes in the structure of the models used and in the magnitude of exogenous "shocks" hitting the models. Although there have been changes in the structure and estimated coefficients of the FRB/US model (for example, a flatter Phillips curve in recent 
Figure 7. Distribution of Outcomes under the Simple Rule

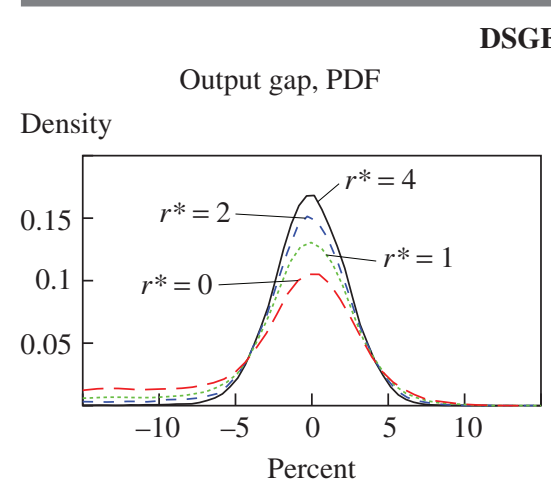

Inflation, PDF

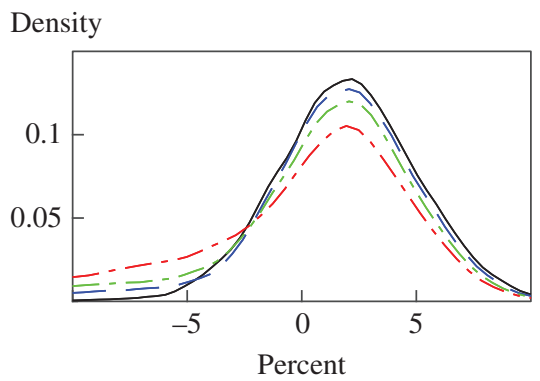

Nominal interest rate, PDF

Density

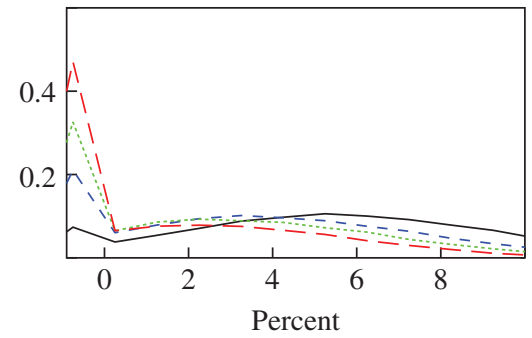

Probability

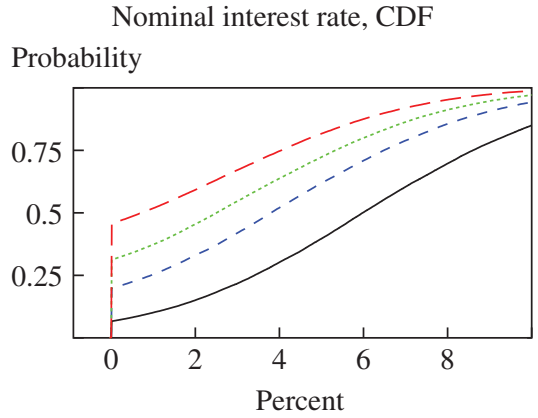

Probability

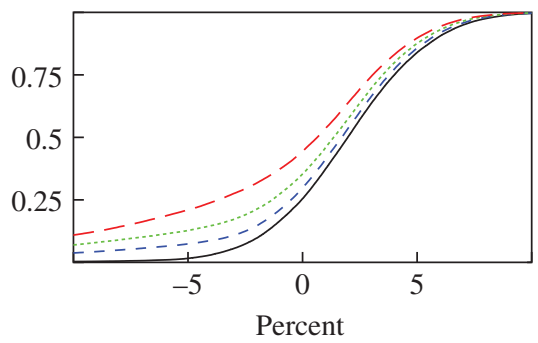

Nominal interest rate, $\mathrm{CDF}$ 
Figure 7. Distribution of Outcomes under the Simple Rule (Continued)

\section{FRB/US model}

Output gap, PDF

Density

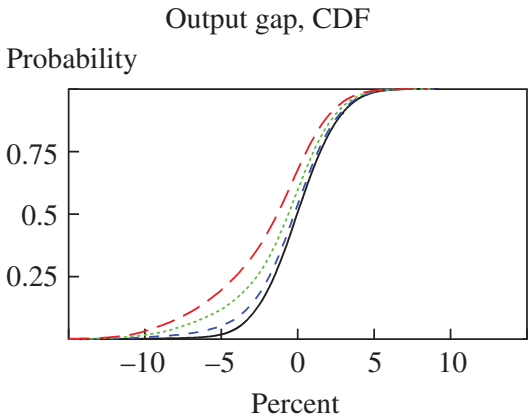

Inflation, PDF

Inflation, $\mathrm{CDF}$

Density

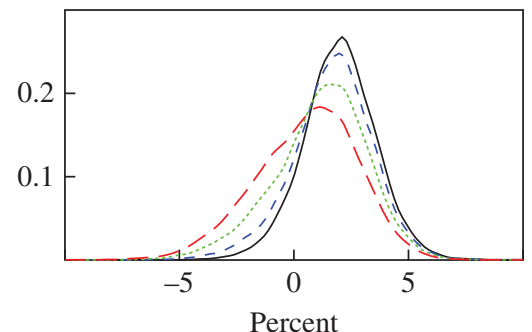

Nominal interest rate, PDF

Density
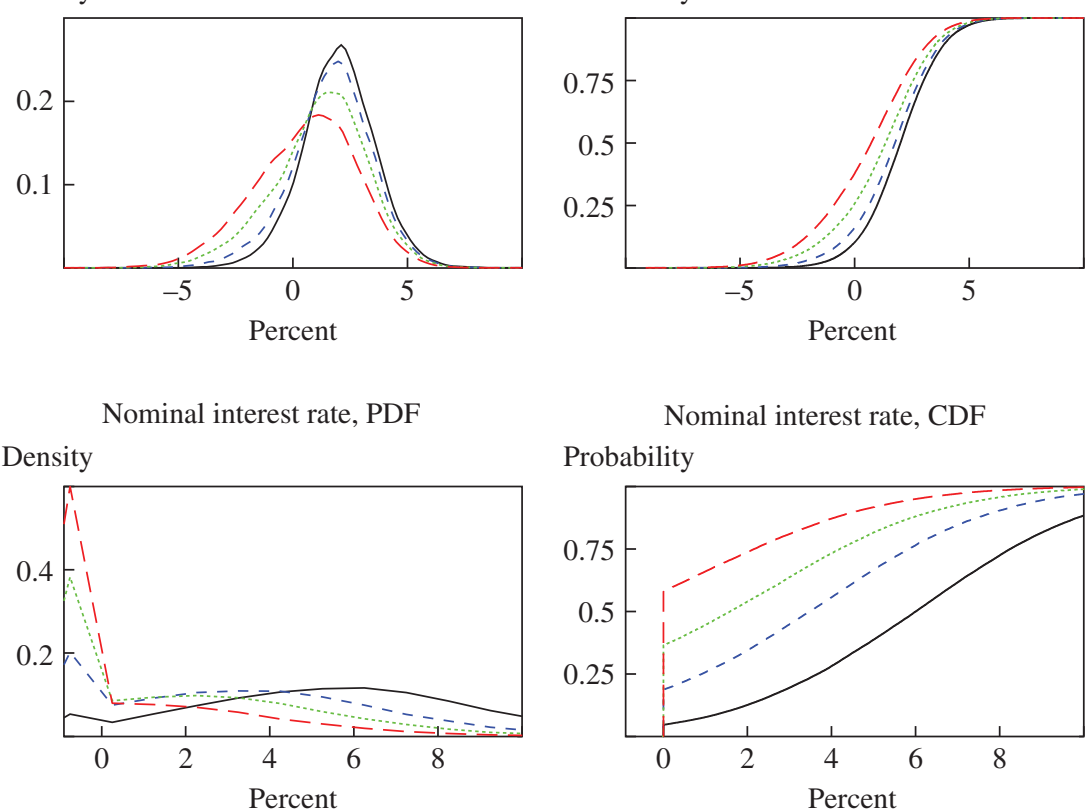

Nominal interest rate, $\mathrm{CDF}$ Probability

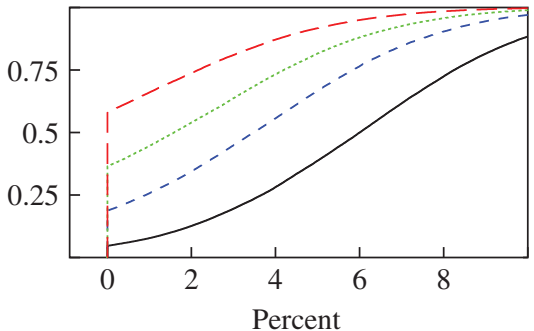

Sources: Federal Reserve Board; Lindé, Smets, and Wouters (2016); authors' calculations. 
vintages), these changes do not account for the different assessment from FRB/US.

Rather, the key drivers of the different perspective are twofold. First, we abstract from adjustments from the simple Taylor (1993) policy rule that add accommodation beyond that prescribed by the base form of the rule. In contrast, Williams (2009) and the main case emphasized by Coibion, Gorodnichenko, and Wieland (2012) include features that amount to commitments to making up accommodation forgone because of the ELB.

Concretely, Williams (2009) reports simulation results for the same simple rule as in the previous subsection. In those simulations, the rule is adjusted to provide additional accommodation when the output gap or inflation deviates from objective values. For example, under Williams's (2009) parameterization, an output gap of -5 percent for a two-year period results in a setting for the federal funds rate approximately $13 / 4$ percentage points below the prescription of the simple rule, and this accommodation decays at a rate of 0.05 per quarter. This feature yields substantial additional accommodation beyond the prescription of the simple rule following an ELB episode. In addition, Williams (2009) only strictly enforces the ELB for up to 4 years, whereas we strictly enforce the ELB for up to 15 years. Figure 8 presents the implications of these assumptions for the frequency with which the ELB binds and the average deviation of output from potential across simulations, for an equilibrium real interest rate of 1 percent (and hence a nonstochastic steady-state interest rate of 3 percent). In these simulations, the version of FRB/US used is the same as that of Williams (2009). Under the approach of Williams (2009), the ELB binds 16.4 percent of the time and output falls 0.2 percent below potential, on average. Removing the adjustment to the simple rule that provides additional accommodation raises the frequency with which the ELB binds to 26 percent and brings the shortfall in output relative to potential to 1 percent, on average. Allowing the ELB to bind for up to 60 quarters increases the frequency with which the ELB binds to 40.3 percent. Comparing these values with those reported in table 3 (and reported as the last bar in each figure) shows that the frequency with which the ELB binds and the effect on output are essentially identical in the version of the FRB/US model used herein and that of Williams (2009), under common assumptions.

An investigation of differences between our results and those from previous DSGE model investigations suggests that similar factors explain why we find more severe constraints from the ELB. In particular, Coibion, Gorodnichenko, and Wieland (2012) present results for an estimated rule that includes lagged interest rates, similar to that above. In their simulations, 
Figure 8. Comparison of Our Results with Those of Williams (2009) for a Steady-State Nominal Interest Rate of 3 percent

\section{ELB frequency}

Percent

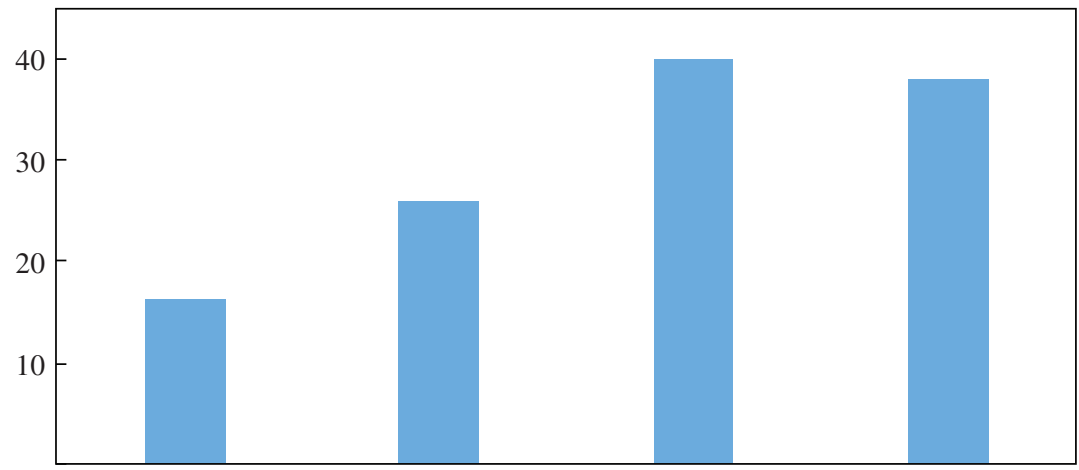

Williams's (2009) Remove Allow ELB to Our analysis approach extraordinary bind 60 quarters accommodation

\section{Mean output gap}

Percent

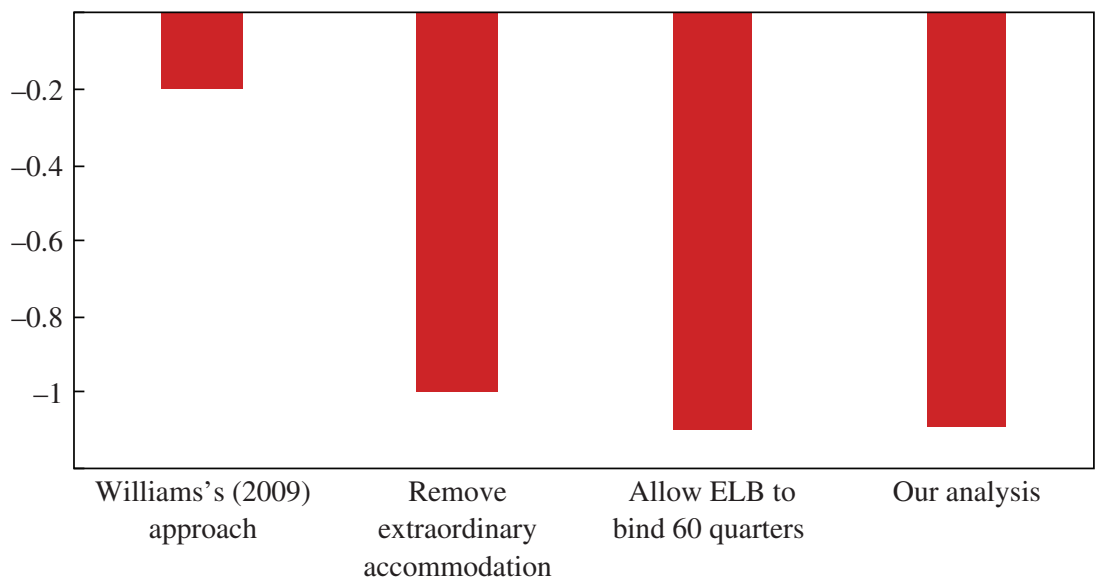

Sources: Federal Reserve Board; Lindé, Smets, and Wouters (2016); Williams (2009); authors' calculations. 
they keep track of the negative values that the policy rate would obtain absent the ELB, setting the actual nominal interest rate equal to this shadow rate when the shadow rate is nonnegative. As we discuss in section VI, this feature implies a commitment to deliver accommodation long after the ELB would otherwise bind. Removing this assumption from their analysis implies the ELB is substantially more problematic than the authors find..$^{13}$ Indeed, economic performance is poor for the simple Taylor (1993) rule they analyze, as herein.

\section{Achieving the Inflation Target: A Risk Adjustment Strategy}

The strategies considered above involve a policy rule whereby inflation is guided back to 2 percent, over the long run, in the absence of shocks. However, shocks to the economy and the inability to provide accommodation in certain circumstances imply that inflation averages less than 2 percent and output systematically falls short of potential when $r^{*}$ is at a moderate to low level. As emphasized by Reifschneider and Williams (2000), Williams (2009), and Nakata and Schmidt (2016), a risk adjustment assumes that policy is more accommodative, on average, than simple Taylor-type rules would imply, and can bring average inflation back to 2 percent. To examine this idea, we consider the following rule:

$$
i(t)=r^{*}-\text { risk adjustment }+2+1.5\left[\pi_{4}(t)-2\right]+y(t) .
$$

Note that, in the absence of shocks, this rule would be expected to bring inflation to a level of 2 percent, plus twice the risk adjustment. One interpretation of this observation is that policymakers systematically aim to achieve inflation somewhat above the long-run target of 2 percent, when they can, so as to achieve the assumed 2 percent objective, as their strategy takes into account the average drag on inflation imposed by the ELB.

The first set of panels in figure 9 presents results regarding the magnitude of the necessary risk adjustment in the DSGE model. As is shown in table 3, the approach without a risk adjustment leads to inflation below its objective for low $r^{*}$, and the top panel of the figure illustrates this shortfall. To compensate for this shortfall, a risk adjustment that yields more accommodative policy is needed to bring inflation to a 2 percent target. Given the

13. Strictly speaking, their code cannot find a solution under this case for a steady-state nominal interest rate of 3 percent, presumably because outcomes diverge uncontrollably. 
Figure 9. Risk Adjustments to the Simple Rule

DSGE model

Average inflation without risk adjustment

Percent

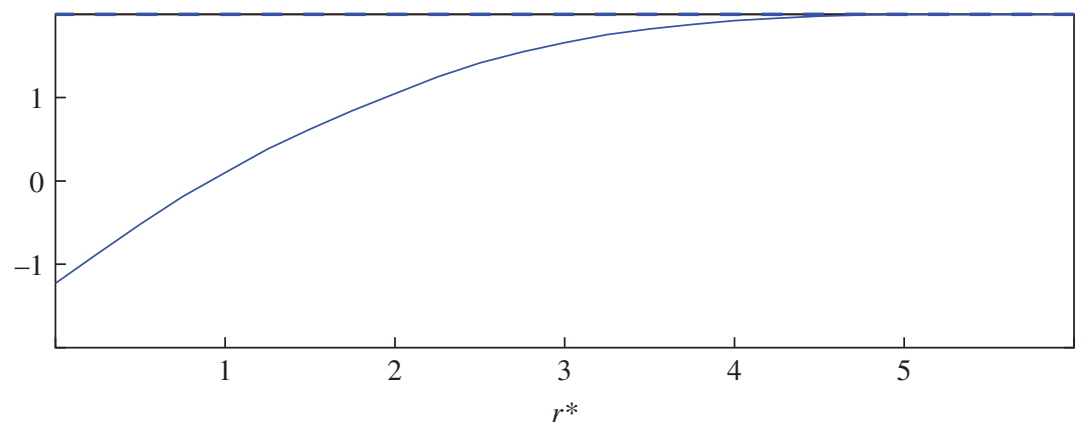

Risk adjustment to achieve 2 percent inflation

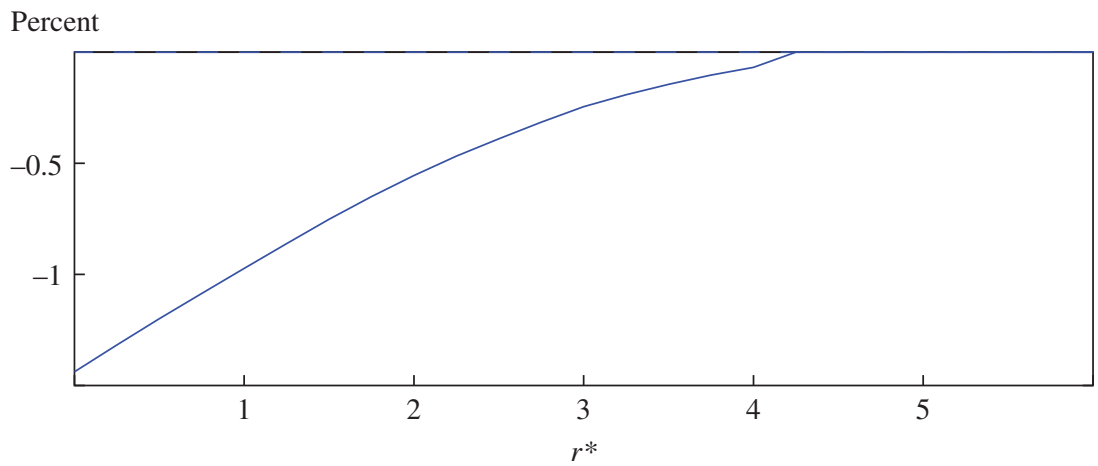

Average shortfall of output from potential risk adjustment

Percent

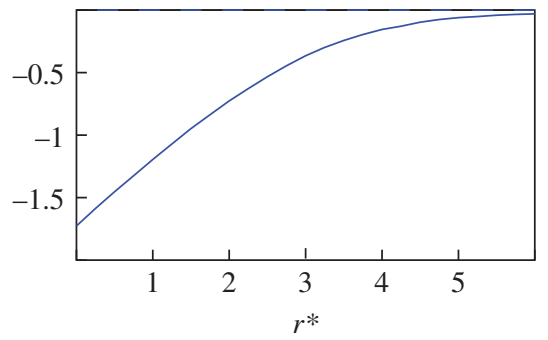

Average inflation when interest rate exceeds ELB

Percent

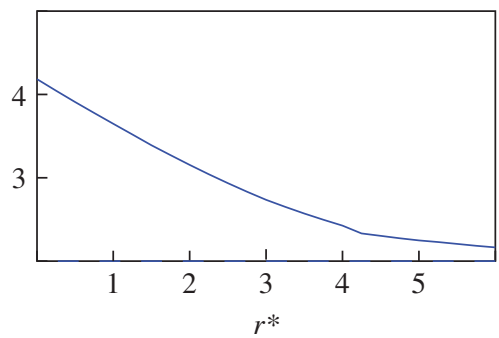

(continued) 
Figure 9. Risk Adjustments to the Simple Rule (Continued)

\section{FRB/US model}

Average inflation without risk adjustment

Percent

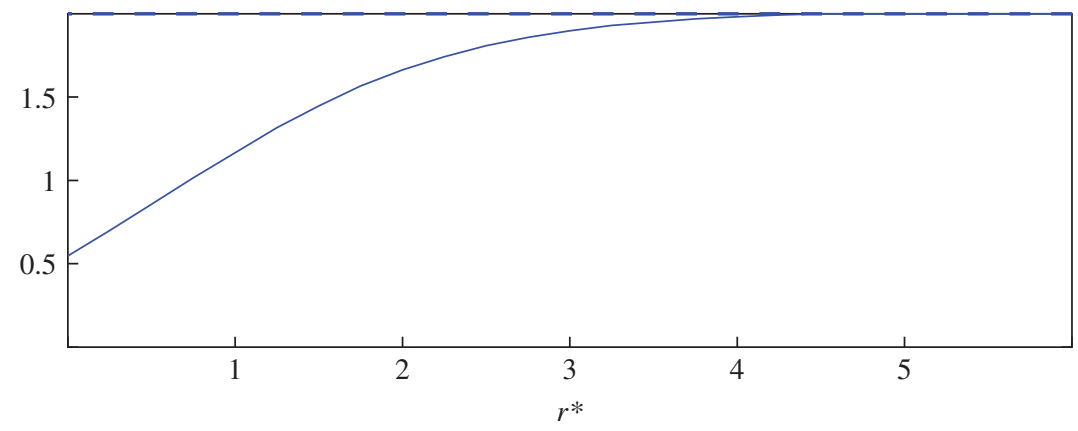

Risk adjustment to achieve 2 percent inflation

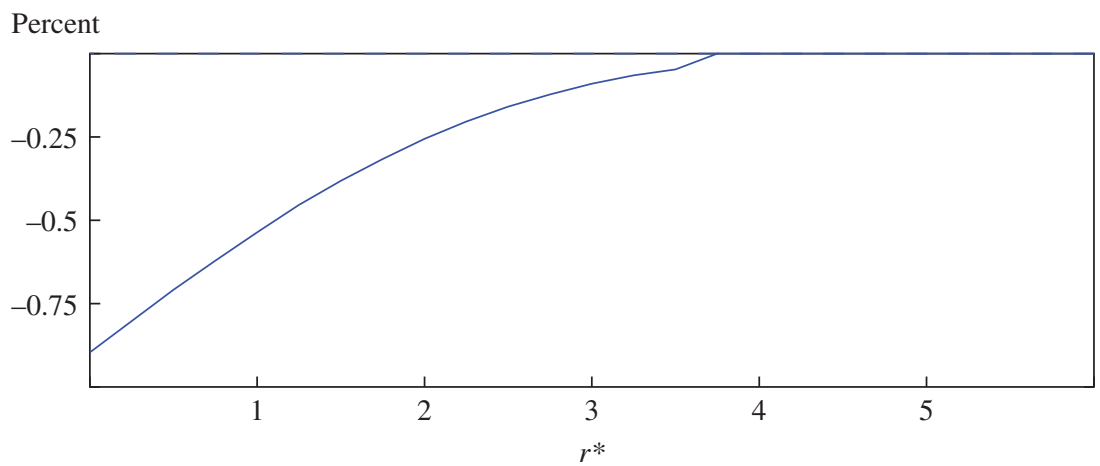

Average shortfall of output from potential risk adjustment

Percent

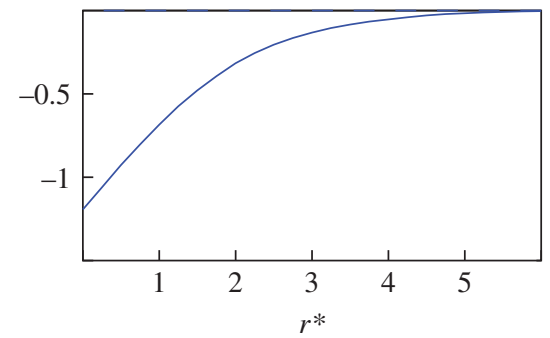

Average inflation when interest rate exceeds ELB

Percent

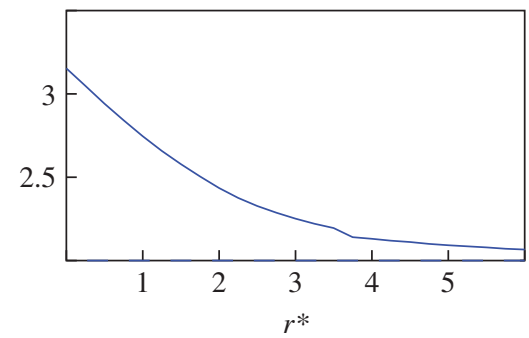

Sources: Federal Reserve Board; Lindé, Smets, and Wouters (2016); authors' calculations. 
large shortfall of inflation relative to its objective when $r^{*}$ is low, sizable adjustments—on the order of 100 basis points for an $r^{*}$ of 1 percentare required to achieve inflation of 2 percent on average, as shown in the middle panel of figure 9. Nonetheless, these adjustments still leave output performance subpar-for $r^{*}$ equal to 1 percent, the output gap across simulations falls short of potential by $1 / 2$ percent, on average, as illustrated in the lower left panel. Overall, these results point to the ability of a risk adjustment to ensure that a 2 percent inflation objective is achieved, on average.

The second set of panels in figure 9 presents analogous results for the FRB/US model. Average inflation performance under a Taylor-type strategy falls short of the 2 percent objective by a more moderate amount than in the DSGE model for $r^{*}$ of 1 percent, as can be seen by comparing the rows in table 3 for nonstochastic steady-state nominal interest rates of 3 percent for each model. And a risk adjustment of approximately 50 basis points brings inflation to the 2 percent objective, on average, in the FRB/ US model, as shown in the middle panel. As in the DSGE model, output remains notably below potential, on average, with the risk-adjusted policy, as shown in the lower-left panel.

In both models, the risk-adjusted strategy (for $r^{*}$ near 1 percent) is consistent with inflation of about 3 percent in the absence of shocks. With shocks buffeting the economy and interacting with the ELB, inflation averages 2 percent, below the implied nonstochastic level consistent with the model. Because inflation and the level of output relative to potential are linked in the models through a Phillips curve relationship, inflation below the implied steady-state level must be accompanied by output below potential, on average. It is important to note that this relationship essentially amounts to a long-run trade-off between inflation and output, and the presence of such a trade-off hinges importantly on the anchoring of long-run inflation expectations that we have assumed in our simulations. A level of activity below potential, on average, could risk an unanchoring of inflation expectations from policymakers' assumed objective of 2 percent. We will return to this potential challenge-and related challenges associated with other strategies we discuss-in the concluding section.

All told, a key takeaway is that the risk adjustment strategy can be effective in bringing inflation to a given objective (such as 2 percent), but may be less effective in addressing the deterioration in the level and volatility of economic activity. 


\section{A Higher Inflation Target: Benefits and Costs}

If a low value of the equilibrium real interest rate causes the economy to encounter the ELB more often, a natural reaction might be to boost the inflation target: According to the Fisher equation, higher average inflation would imply a higher average value of nominal interest rates, and so the ELB would be encountered less frequently. A number of authors have proposed such a change in policy, notably Blanchard, Dell'Ariccia, and Mauro (2010); Ball (2014); and Ball and others (2016).

Although an increase in the inflation target would have the benefit of reducing the frequency of encountering the ELB, higher average inflation would come with its own set of costs. An extensive body of literature on the implications of higher average inflation for economic welfare considers a broad range of mechanisms, and these are, for the most part, not directly considered in our simulations, and may be inadequately captured in the models we examine. For example, Martin Feldstein (1997) and Andrew Abel (1997) suggest that taxation of nominal capital income implies substantial effects of changes in the inflation target on the long-run productive capacity of the economy. Another example is the cost of money holdings that underlie the optimality of Milton Friedman's (1969) rule in some models. The New Keynesian literature has emphasized the effects of steadystate inflation on price dispersion; such effects are not present in FRB/US and are not the focus in our analysis of the DSGE model, which we employ largely for its empirical predictions regarding output, inflation, and interest rates. ${ }^{14}$ Kiley, Mauskopf, and Wilcox (2007) review various strands of the literature on the costs of inflation. ${ }^{15}$

The importance of these costs remains controversial. As discussed by Coibion, Gorodnichenko, and Wieland (2012), in New Keynesian models, most of the costs associated with inflation arise from steady-state inflation, rather than inflation fluctuations. Indexation or alternative notions of nominal rigidity may alter the relative weight on these factors in economic welfare. For example, Nakamura and others (2016) note that the commonly used Calvo (1983) specification implies costs of price dispersion that are an order of magnitude larger than plausible other models. ${ }^{16}$ They

14. Woodford (2003) is the classic reference. Schmitt-Grohé and Uribe (2011) review much of the related literature.

15. Their analysis builds on Fischer (1981).

16. This insight is closely related to the discussion in Kiley (2002) of the magnification of price dispersion in Calvo (1983) models relative to other models of price stickiness. Nakamura and others (2016) go beyond this point in their empirical and calibration exercises. 
then present empirical evidence suggesting that the link between inflation and price dispersion may be more muted than in the earlier literature. An overall assessment would require more research to pull together a range of effects-as was done by Stanley Fischer (1981) and Kiley, Mauskopf, and Wilcox (2007)_including the effects on price dispersion emphasized in the New Keynesian literature, the interaction of the nominal tax code with the trend rate of inflation, and a reassessment of the costs associated with money holdings given changes in transaction technologies and the legal authority to pay interest on bank reserves.

In light of the uncertainty and debate surrounding the costs associated with higher trend inflation, we take a pragmatic approach to assessing economic welfare of the outcomes from the various models and monetary policy strategies we consider. We assume an ad hoc loss function that is similar to one commonly used in central bank analysis. ${ }^{17}$ We view such a specification as being the closest possible to current "conventional wisdom"; we return at the end of the discussion to a consideration of the limitations of this approach.

In particular, suppose that economic welfare can be approximated by the loss function

$$
E\left\{\left[\pi(t)-\pi^{\text {optimal }}\right]^{2}+\gamma\left[y(t)-y^{\text {optimal }}\right]^{2}\right\} .
$$

In this formulation, economic losses equal the expected value of squared deviations of inflation and output from their optimal values, and $\gamma$ is the weight on output gaps relative to that on inflation gaps. ${ }^{18}$ With this loss function, we can use the distributions of simulated outcomes under alternative values of the inflation target to estimate economic losses. We consider three cases:

-Case 1: The optimal inflation rate is assumed to be 2 percent, and the optimal level of output is consistent with an output gap of zero. In addition, $\gamma$ equals 0.25 , a value consistent with a relative weight on deviations of the unemployment rate from its natural rate of 1 and an Okun's law coefficient linking the unemployment gap to the output gap of $1 / 2 .{ }^{19}$

17. See, for example, the speech by Yellen (2012).

18. Coibion, Gorodnichenko, and Wieland (2012) undertake a similar assessment of the optimal rate of inflation. A key difference is that they derive their loss function from the underlying welfare problem in their model, whereas we posit an ad hoc loss function.

19. Yellen (2012) puts equal weight on inflation and unemployment gaps, and uses an Okun's law coefficient of $1 / 2$ (that is, unemployment gaps are $1 / 2$ as large as output gaps). 
- Case 2: Parameters are the same as in case 1, except the weight on output $\gamma$ is raised to 1 . This weight is substantially higher than in most research, including that deriving $\gamma$ from micro foundations.

-Case 3: Parameters are the same as in case 2, but the optimal inflation rate equals 0 .

These cases span economically important situations. First, the general form of the loss function echoes that often used in the New Keynesian literature. ${ }^{20}$ Second, cases 1 and 2 yield an optimal inflation rate of 2 percent abstracting from the ELB, and hence can provide a sense of how much a binding ELB may shift the desirable rate of inflation away from a level that was chosen by a number of inflation-targeting central banks before recent ELB experience. Finally, case 3-in which the optimal inflation rate is zero when the ELB is not a consideration-is most consistent with typical discussions of the potential costs of inflation. ${ }^{21}$ Nonetheless, important cases also fall outside these assumptions; in particular, these cases do not include one in which the socially optimal level of output exceeds the productive capacity of the economy (because distortions lead economic activity to fall short of an optimal level).

The first set of panels in figure 10 presents losses as a function of the average level of inflation (the inflation target) from the FRB/US model simulations for values of the equilibrium real interest rate from 1 to 3 percent. As illustrated by the left panel, $r^{*}$ equal to 3 percent leads to an optimal inflation level very close to 2 percent when the welfare function assumes zero losses at 2 percent inflation and the weight on output is $1 / 4$. Because optimal inflation in the stochastic case is close to the point at which the loss function achieves its minimum absent shocks, we can infer that the ELB has little effect on the optimal inflation rate. By contrast, in case 3 (a loss function in which zero inflation is desirable absent shocks), the optimal inflation rate is close to 1 percent when $r^{*}$ is 3 percent. As $r^{*}$ falls, the optimal inflation rate rises, as the effects of the ELB become more pronounced. For example, in case 1 , the optimal inflation rate when $r^{*}$ equals 1 percent approaches $2 \frac{1}{2}$ percent. In case 3 , the optimal inflation rate is about 2 percent when $r^{*}$ equals 1 . Here, the effect at the margin of a lower $r^{*}$ is somewhat great, but the implied value of optimal inflation is nonetheless consistent with current inflation targets.

The second set of panels in figure 10 presents optimal inflation results for the DSGE model. The overall message is similar-the asymmetries

20. See, for example, Woodford (2003).

21. See, for example, Coibion, Gorodnichenko, and Wieland (2012). 
Figure 10. Alternative Views on Losses at Different Levels of the Inflation Target

\section{FRB/US model}

Alternative $r^{*}$

Losses

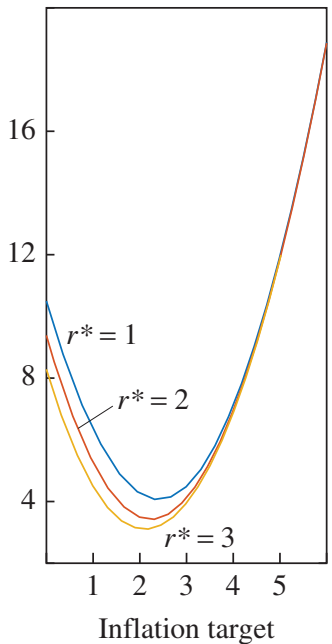

Alternative $r^{*}$

Losses

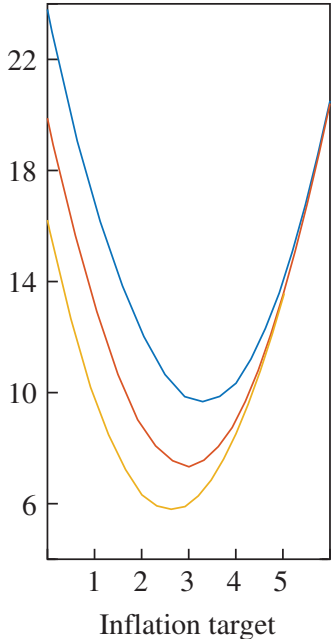

Higher output weight

Losses

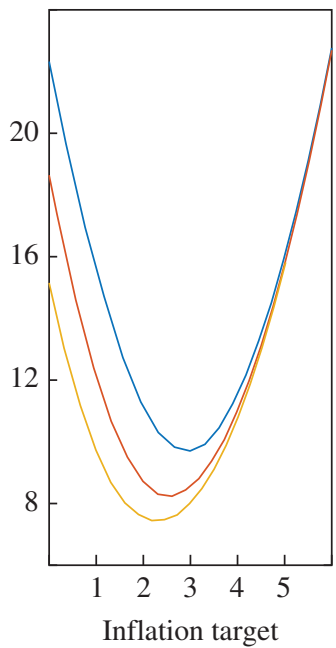

DSGE model

Higher output weight Losses

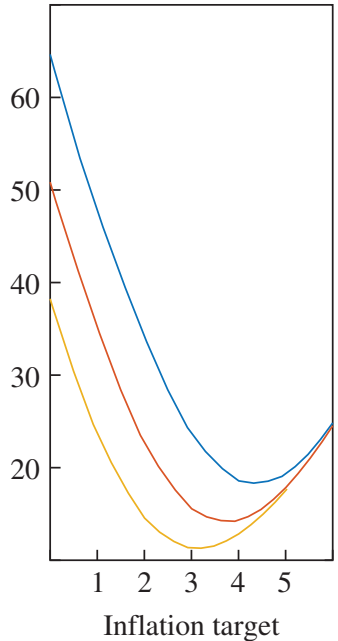

Higher output weight and optimal inflation equals 0

Losses

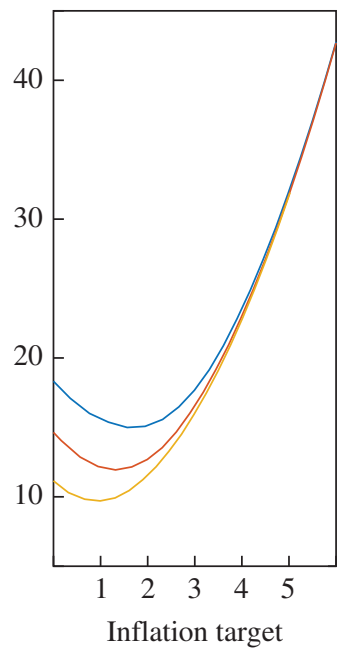

Higher output weight and optimal inflation equals 0

Losses

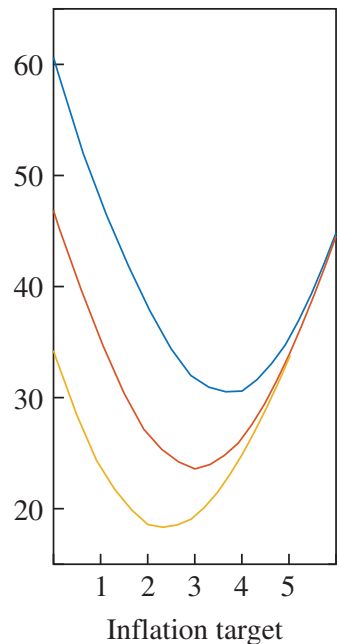

Sources: Federal Reserve Board; Lindé, Smets, and Wouters (2016); authors' calculations. 
in risk implied by the ELB can, under some loss function assumptions, point to an optimal level of inflation above 2 percent. In some of the cases presented, the optimal level of inflation is notably higher than 2 percent, with optimal inflation clustered around 4 percent when $r^{*}$ equals 1 . One reason optimal inflation is so high in the DSGE model is that under the simple policy rule, the ELB implies particularly adverse outcomes in this model, echoing results for the rule found by Coibion, Gorodnichenko, and Wieland (2012). As is shown below, other policy strategies lead to notably better outcomes near the ELB in the DSGE model.

These calculations and our earlier results point to several key questions that are likely to determine the desirable level of the inflation target in an environment where monetary policy is constrained to follow a simple strategy akin to a Taylor-style rule:

-What are the costs associated with steady-state inflation versus inflation volatility? If a steady trend rate of inflation is very costly, as in much of the literature, the optimal level of inflation would be much lower than if the primary costs associated with inflation stem from volatility or uncertainty.

-What is the relative weight that should be placed on fluctuations in economic activity? A relatively modest weight often emerges from the "micro foundations" of DSGE models-which typically assume, for example, perfect insurance across individuals regarding consumption and labor market fluctuations. More recent research (see, for example, Ravn and Sterk 2017) allows for heterogeneity across households and imperfect insurance, and related approaches may lead to different conclusions about the relative costs of fluctuations in economic activity.

- How large are distortions that imply that the level of economic activity is below its optimal level? On one hand, distortions that imply the socially optimal level of output exceeds productive potential would imply that the shortfalls in output relative to potential associated with the interaction of a low inflation target and the ELB are costlier than in our illustrations. On the other hand, Barro and Gordon (1983), and their successors, have argued that such distortions would make it difficult for a central bank to maintain low and stable inflation.

A satisfactory analysis of this range of questions is left for future work.

\section{Commitment Strategies}

In this section, we move beyond the approaches using a traditional, simple rule to an approach that better captures the New Keynesian literature's emphasis on commitments to maintain policy accommodation for a longer 
period - that is, forward guidance of the Odyssean variety in the lexicon of Campbell and others (2012) — as a means for lowering the adverse effects of an ELB.

\section{VI.A. A Rule with Commitment}

Here, we consider a policy rule in which the change in the nominal interest rate responds to the deviation of inflation from an inflation objective of 2 percent and the output gap: ${ }^{22}$

$$
\Delta i(t)=0.125\left[\left(\pi_{4}(t)-2\right)+y(t)\right] .
$$

We consider two ways in which this rule could be followed. We refer to the first as a naive implementation of the rule. In this implementation, we assume that policymakers take the lagged value of the nominal interest rate entering the rule to be equal to the actual lagged value. This assumption implies that the short-term interest rate is increased from the ELB as soon as the weighted average of inflation and the output gap in the rule exceed their objectives. It also implies that the ELB is not accompanied by any commitment to extraordinary accommodation beyond that prescribed by the rule. One might nonetheless interpret the rule as implying extraordinary accommodation relative to a Taylor (1993) rule, as it embeds a commitment not to raise the interest rate until the average of inflation and output exceed their objectives.

In the second implementation of the rule, we introduce a commitment to remain more accommodative than the naive implementation of the rule following a period in which the ELB binds. The idea is to keep track of the "shadow" rate of interest-that is, the interest rate that would have prevailed if the ELB had not applied - and not raise interest rates until the shadow rate rises above the effective lower bound. Algebraically, we can define the shadow rate, $i^{*}$, as

$$
i^{*}(t)=0.125\left[\pi_{4}(t)-2\right]+0.125 y(t)+i^{*}(t-1) .
$$

The policy rate is then set equal to the maximum of this shadow rate and the ELB:

$$
i(t)=\max \left[i^{*}(t), i^{E L B}\right]
$$

22. In equation 5, the nominal interest rate is expressed at an annual rate and that the four-quarter rate of inflation, $\pi_{4}(t)$, equals the average of inflation in the current and previous three quarters: $\sum_{i=0}^{3} \pi(t-i)=\sum_{i=0}^{3}(1-L) p(t-i)$, where $L$ is the lag operator. 
Under this rule, the shadow rate will continue to fall if output and inflation fall below their objectives during an ELB episode, and the nominal interest rate will not rise above the ELB until the shadow rate rises above the ELB - which will not occur until sometime after the average of inflation and output rise above their objectives. This mechanism is related to the one proposed by Reifschneider and Williams (2000), who suggest that policymakers keep track of the forgone decline in interest rates implied by an ELB and commit not to raise the short-term policy rate above the ELB until this stock of forgone cuts in interest rates has been exhausted. As we noted above, Coibion, Gorodnichenko, and Wieland (2012) employ a similar shadow rate adjustment, and this commitment assumption is central to their finding that the ELB is only mildly binding in their DSGE model.

There are several reasons to consider such rules. First of all, like the empirical rule of subsection III.A, both versions of this rule include an important weight on the lagged nominal interest rate-indeed, our change rule goes further than the empirical rule and assumes a coefficient of 1 . There is a large body of literature discussing why introducing lags of the policy rate into a policy rule improve its performance away from the ELBsee Woodford (2003) for a summary. Intuitively, adding the lagged value of the federal funds rate tends to make the rule more effective, because doing so makes changes in the federal funds rate more persistent. Greater persistence will mean that any given change in interest rates will have a larger impact on long-term interest rates, and in most macroeconomic modelsincluding the FRB/US model and our DSGE model-long-term interest rates are most relevant for spending. As a comparison of tables 2 and 3 indicates, the empirical rule performs somewhat better than the simple rule, especially in the DSGE model, and the presence of lagged inflation is one reason why.

Second, the naive version of the rule implies that the nominal interest rate will remain at its ELB until either inflation rises above the 2 percent target or output rises above potential once the ELB has been reached. As a result, the equation captures risk management considerations emphasized in recent discussions: Campbell and others (2012) consider the role of thresholds for economic activity or inflation in determining exit from the ELB in their discussion of Odyssean forward guidance and risk management, and the rule implies thresholds of output equal to potential (or, equivalently, an unemployment rate threshold at the natural rate). In addition, Charles Evans and others (2015) argue that the risks associated with a return to the ELB point to a need for policymakers to allow some overshooting by either inflation or output relative to its long-run objectives before removing 
policy accommodation once an ELB episode has begun-and a rule that does not remove accommodation until at least one of the goal variables overshoots guarantees such behavior.

Third, a small body of literature has suggested that a rule of this form is a good description of policymakers' behavior during certain historical periods (Fuhrer and Moore 1995; Kiley 2014), and that such a policy may be nearly optimal in simple rules with some features reminiscent of modern macroeconomic models (Fuhrer and Moore 1995). Moreover, the optimal simple rules of Reifschneider and Williams (2000) and Williams (2003) have parameter values fairly close to those in the proposed rule. The near optimality of a rule in which the first difference of the nominal interest rate responds to inflation and the output gap is also consistent with the New Keynesian literature on optimal inertia (Woodford 1999). This connection stems, in part, from the fact that the proposed rule has a price level element absent the ELB, as we discuss next.

Finally, the shadow rate version of the rule can also be interpreted as a type of flexible price level targeting, connecting our discussion of a commitment approach to that literature. Integrating backward, the rule can be rewritten as $^{23}$

$$
i(t)=0.125\left\{\sum_{i=0}^{3}[p(t-i)-0.5 t]+\sum_{j=0}^{\infty} y(t-j)\right\} .
$$

Here, the rule responds to the average of the price level during the most recent four quarters relative to a trend that increases at a 2 percent annual rate per period, as well as to the entire history of deviations of output from potential. A simple version of the first component of the rule (for example, the current price level) is shared with price level targeting and nominal income targeting rules. The second component would not be present in a pure price level rule; in a nominal income targeting rule, only the current value of the output gap would be present, not the entire history of output gaps. Rules that include a price level element, as in the shadow rate version of our rule, have been shown to be quite valuable in stabilizing the economy and have been discussed as a potential commitment approach, especially in discussions of the effective lower bound (Woodford 2003).

23. It is instructive to walk through the steps delivering the price level terms. The inflation terms above are $\sum_{i=0}^{3} \pi(t-i)-2$, which equals $\sum_{i=0}^{3}[(i-L) p(t-i)-0.5]$. Multiplying by the inverse of $(1-L)$ yields $\sum_{i=0}^{3}[p(t-i)-0.5 t]$. 
Table 4. The Performance of a Difference Rule with and without Shadow Rate Adjustment

\begin{tabular}{|c|c|c|c|c|c|c|}
\hline $\begin{array}{l}\text { Nominal } \\
\text { interest } \\
\text { rate }\end{array}$ & $\begin{array}{c}E L B \\
\text { frequency } \\
\text { (percent) }\end{array}$ & $\begin{array}{c}\text { Mean } \\
\text { duration } \\
\text { of ELB } \\
\text { (quarters) }\end{array}$ & $\begin{array}{l}\text { Mean } \\
\text { output } \\
\text { gap }\end{array}$ & $\begin{array}{c}\text { Mean } \\
\text { inflation rate } \\
(\text { target }=2.0)\end{array}$ & $\begin{array}{l}\text { Root mean } \\
\text { square } \\
\text { deviation of } \\
\text { output gap }\end{array}$ & $\begin{array}{c}\text { Root mean } \\
\text { square } \\
\text { deviation } \\
\text { of inflation } \\
\text { rate }\end{array}$ \\
\hline \multicolumn{7}{|c|}{ DSGE, without shadow rate adjustment } \\
\hline 5 percent & 0.8 & 4.9 & 0.0 & 2.0 & 2.4 & 2.1 \\
\hline 4 percent & 3.4 & 6.2 & -0.1 & 2.0 & 2.5 & 2.1 \\
\hline 3 percent & 10.4 & 9.0 & -0.5 & 1.6 & 3.4 & 2.8 \\
\hline \multicolumn{7}{|c|}{ DSGE, with shadow rate adjustment } \\
\hline 5 percent & 0.9 & 6.1 & 0.0 & 2.0 & 2.4 & 2.1 \\
\hline 4 percent & 3.6 & 7.7 & 0.0 & 2.0 & 2.5 & 2.1 \\
\hline 3 percent & 9.6 & 9.3 & 0.0 & 2.0 & 2.5 & 2.1 \\
\hline \multicolumn{7}{|c|}{ FRB/US, without shadow rate adjustment } \\
\hline 5 percent & 5.3 & 7.2 & -0.1 & 2.0 & 2.3 & 1.4 \\
\hline 4 percent & 12.4 & 8.0 & -0.4 & 1.9 & 2.7 & 1.5 \\
\hline 3 percent & 29.7 & 10.8 & -1.4 & 1.5 & 3.8 & 1.8 \\
\hline \multicolumn{7}{|c|}{ FRB/US, with shadow rate adjustment } \\
\hline 5 percent & 6.1 & 9.6 & 0.0 & 2.0 & 2.3 & 1.4 \\
\hline 4 percent & 12.0 & 11.1 & 0.0 & 2.0 & 2.3 & 1.4 \\
\hline 3 percent & 22.0 & 13.8 & -0.1 & 2.0 & 2.5 & 1.4 \\
\hline
\end{tabular}

Sources: Federal Reserve Board; Lindé, Smets, and Wouters (2016); authors' calculations.

\section{VI.B. Outcomes}

Table 4 presents, in the first and third panels, results for the DSGE and FRB/US models, respectively, under the naive version of the rule. As can be seen on the first line of each panel, the rule delivers good economic performance when the steady-state nominal interest rate is relatively high, with the standard deviations of both inflation and the output gap below the values achieved under either the estimated rule or the simple rule in both models. Performance remains very good under this rule in both models for a steady-state nominal interest rate as low as 4 percent, but deteriorates for lower values of the steady-state nominal interest rate.

The structure of the rule contributes to the limited gains in performance achieved relative to our earlier, noncommitment rules. In particular, the rule continues tightening policy for as long as inflation or output exceeds its objective, which can be quite restrictive. At low values of the steadystate nominal interest rate, this latter property dominates the stimulative 
properties that accompany continued loosening in policy when inflation and output fall short of their objectives because the ELB limits accommodation and the period after an ELB episode is followed by a pronounced tightening in the monetary stance.

Overall, these results suggest that a policy approach in which the nominal interest rate is not increased until either inflation or output sufficiently exceeds its long-run objective-that is, thresholds for exiting the ELB are equal to the inflation target and the natural rate of unemployment, respectively - may capture part of the risk management approach suggested by Evans and others (2015). However, the very aggressive tightening in policy implied by a difference rule of this type may be too restrictive to promote recovery absent an additional element.

The second and fourth panels of table 4 present results under this shadow rate implementation for the DSGE and FRB/US models, respectively. In both models, such a commitment effectively eliminates any deterioration in economic performance associated with an ELB. This result is reminiscent of a core result from simple New Keynesian models: Policymakers capable of committing to possibly very accommodative policies can essentially remove the pernicious effects of the ELB.

\section{VI.C. Inflation Targets under Commitment Policies}

Our results in section $\mathrm{V}$ suggested that lower levels of the equilibrium federal funds rate could imply some increase in the optimal rate of trend inflation, with the effects especially pronounced in the DSGE model. Those results, however, assumed that policy was set according to the simple rule. Under that rule, the ELB leads to a substantial deterioration in economic performance. A higher inflation target would lead to an improvement along this dimension, because the ELB would be encountered less often. As table 4 makes clear, macroeconomic performance is considerably better under the policy rule with the commitments we have assumed than under the simple policy rules. In particular, under the change rule that accumulates forgone accommodation in a shadow interest rate, there is hardly any deterioration in macroeconomic performance as the equilibrium real federal funds rate declines. Under commitment approaches such as these, the stabilization benefit from raising the inflation target is considerably smaller than under the simpler rules. As a consequence, the case for raising the inflation target effectively disappears under commitment approaches, regardless of one's assessment of the costs of inflation or the relative importance of output fluctuations in the social welfare function. 


\section{VI.D. Can Commitments Be Credible?}

The commitment strategies we have discussed would represent substantial changes from approaches to monetary policy based on traditional simple rules. If policy had historically been set in accordance with a simple rule perspective-which many observers suggest may have been the case before 2007 (Taylor 1993; Taylor and Williams 2010) — then a switch to an approach emphasizing, for example, the change in the interest rate, or providing additional accommodation in the aftermath of an ELB episode, would mark a major change in policy. The extent to which such a major change would be credible is thus an important question.

We view the credibility of a commitment policy as having two components, one concerning the credibility of the policy on announcement, and the other the credibility of the policy once it is established. A key consideration for the announcement of a new policy strategy is the degree to which expectations adapt. We do not explore this issue directly here, but it is reasonable to imagine that some period of adaptation would be necessary—see Reifschneider and Roberts (2006) for illustrative simulations and a discussion. ${ }^{24}$

The credibility of a commitment policy once the policy is well understood raises different questions. In particular, the commitment policies we consider here do not remove accommodation before inflation or activity overshoots its desired levels and may imply inflation that exceeds the central bank's 2 percent target, perhaps by a considerable margin. Such a policy may not be credible because it would not be time consistent: Once free of the ELB, a policymaker would be tempted to tighten policy in order to bring inflation and resource utilization back to their targets. It is important to keep in mind that the credibility of commitments by monetary policymakers is not unique to the "make up" policies we discuss. For example, the risk adjustment strategies discussed above also imply that inflation often overshoots the 2 percent objective-as we showed, inflation must average about 3 percent to reach a 2 percent target under this approach. The fact that such commitment and credibility challenges are pervasive suggests that a key question is whether economic theory and historical experience

24. Reifschneider and Roberts (2006) consider the effectiveness of various strategies to mitigate the effect of the ELB under model-consistent expectations and expectations that are invariant to the policy regime through a set of illustrative simulations. Kiley (2017) shows that commitment policies can be highly effective, even if households' and nonfinancial firms' expectations formation is invariant to the policy regime, so long as financial markets respond to policy communications. 
indicate that a central bank could overcome the temptation to renege on its promises. This question was posed by Barro and Gordon (1983) with respect to whether a central bank would be capable of maintaining low and stable inflation. These authors showed that when equilibrium output is inefficiently low-owing, for example, to monopolistic competition-a promise to maintain low and stable inflation would not be time consistent. Barro and Gordon (1983) then worked out conditions under which commitments by a central bank could be made credible. Subsequent history suggests that central banks' commitments to low and stable inflation can indeed be credible. As the review by Lars Svensson (2010) suggests, central banks have stuck to their inflation targets during extended periods, including across turnovers in the leadership of the central bank, suggesting a role for the reputation of the institution, not just the individuals in place, in shaping the reputational forces that influence the credibility of commitments. ${ }^{25}$ Nakata (2014) has discussed how such reputational effects may make a post-ELB commitment policy credible.

All told, it is reasonable to question whether the types of strategies we discuss could be sustained, but it is also reasonable to consider the possibility that the challenges related to commitment are manageable.

\section{Looking Back at Recent History: A Counterfactual Exercise}

Up to this point, our analysis has been based on simulations during many periods and has been divorced from any set of specific historical conditions. To illustrate the performance of the approaches we have analyzed in a less abstract manner, we consider how the outlook for inflation and economic activity would have evolved (according to our models) if there had been a credible shift toward the approaches analyzed herein in the fall of 2013; these simulations are akin to impulse response analyses of how conditions would have differed if policy changes had been adopted at that time, based on macroeconomic conditions at that point. We chose the fall of 2013 based on several considerations: It matches the period during which Eric Engen, Laubach, and Reifschneider (2015) considered alternative outlooks; it is sufficiently long after the Great Recession to be a plausible candidate for a shift in regime, yet sufficiently far in the past so as

25. "No country has so far abandoned inflation targeting after adopting it (except to join the euro area), or even expressed any regrets" (Svensson 2010, p. 1242). 
not to conflate the general issues we discuss with issues that some readers may see as relevant for current policy debates; and it represents a period during which the outlook involved still sizable slack in labor markets and inflation below its 2 percent objective, to illustrate differences across the policy strategies.

Figure 11 presents results, with the first page of panels giving the results for the FRB/US model and the second page those for the DSGE model. In each case, the line spanning the width of the panel represents the history of the variable through 2013:Q2 and the consensus forecast thereafter, as of October 2013, as reported by Engen, Laubach, and Reifschneider (2015). We assume that this outlook is based on an equilibrium real interest rate $r^{*}$ of 1.6 percent and a natural rate of unemployment of 5.6 percent, as the consensus outlook settles at these values for these variables by 2020 . The FRB/US and DSGE models are matched to this history and projection, and alternative projections are derived by assuming that an alternative monetary policy approach is initiated in the first quarter of 2014.

To be clear, these simulations assume that the new policy is immediately credible. To the extent that this policy differs substantially from policies in place historically, it would probably not be immediately credible-and thus the outcomes we present may not have been attainable circa 2013. Although the performance of a new policy in the immediate aftermath of its adoption is clearly an important consideration, it is also important to assess the performance of policies in a steady state, after transition issues have been worked through.

In the consensus outlook as of October 2013, the nominal federal funds rate remains at zero until the first quarter of 2015, the output gap begins in 2014 at -3 percent and closes gradually, and PCE inflation rises slowly to 2 percent. ${ }^{26}$ Outcomes under the simple rule examined above are essentially identical to the consensus outlook, apparently because the policy approach embedded in this rule does not differ materially from that implicit in the consensus outlook, according to both the FRB/US and DSGE models.

Implementing a risk adjustment to the simple rule of 50 basis points leads to somewhat higher inflation and little change in output in both models. The more accommodative policy approach alters the outlook for the nominal interest rate very little in the FRB/US model, and actually leads

26. To construct the output gap implicit in the consensus outlook, we subtract the unemployment rate from the assumed natural rate of unemployment of 5.6 percent and multiply the resulting unemployment gap by -2 . 
Figure 11. Changes in the Economic Outlook under Alternative Approaches ${ }^{\mathrm{a}}$

FRB/US model

Nominal federal funds rate

Percent

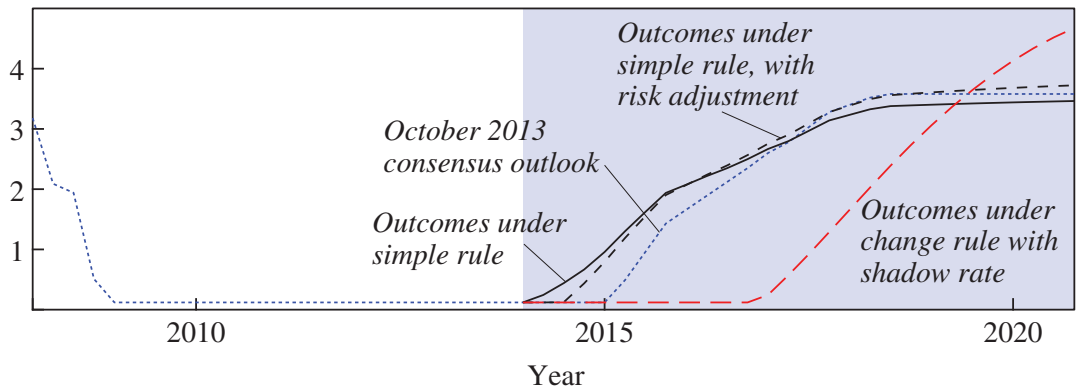

Output gap

Percent

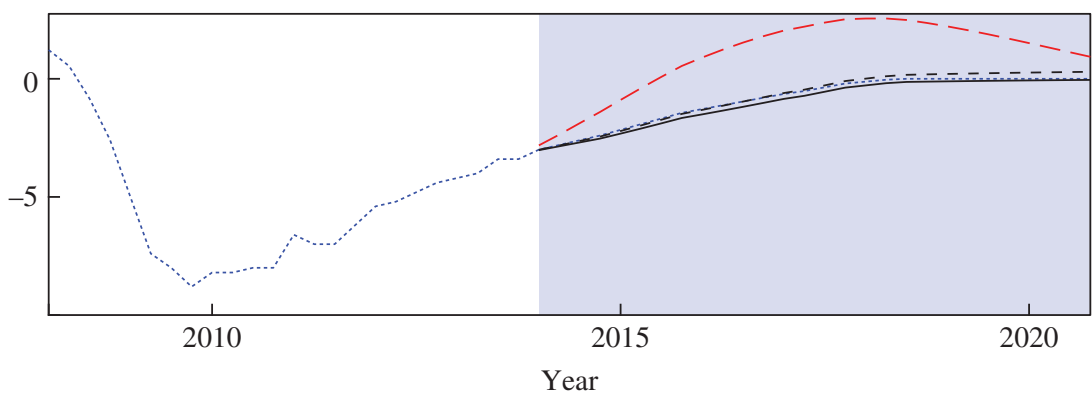

Inflation

Percent

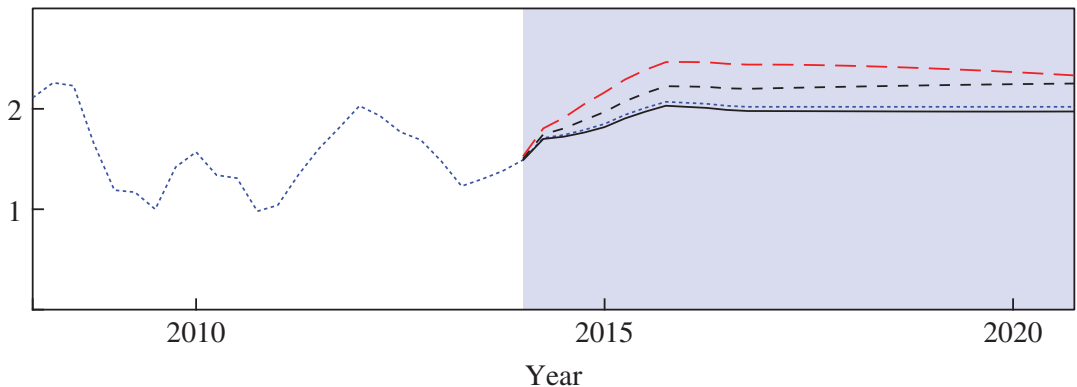

(continued) 
Figure 11. Changes in the Economic Outlook under Alternative Approaches ${ }^{\mathrm{a}}$ (Continued)

DSGE model

Nominal federal funds rate

Percent

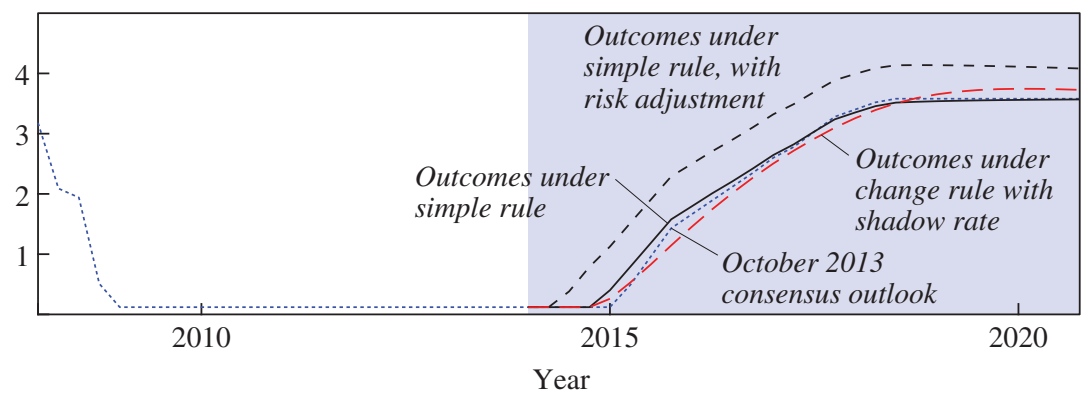

Output gap

Percent

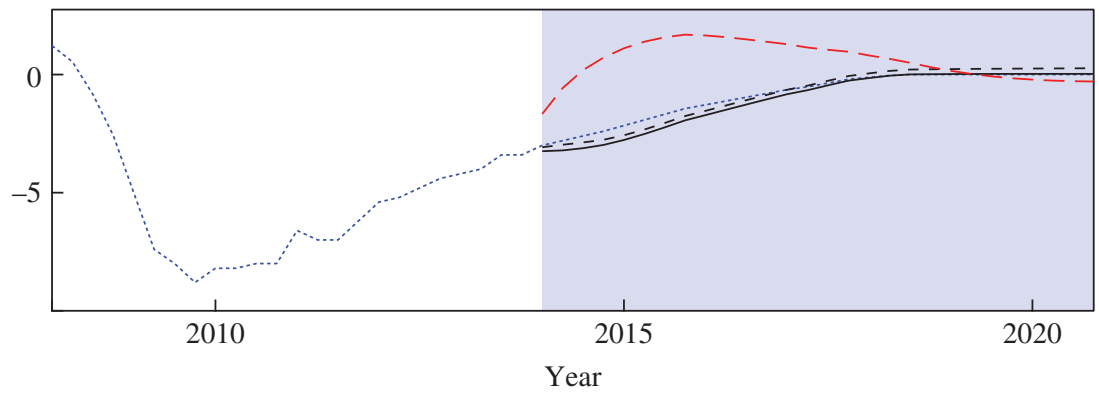

Inflation

Percent

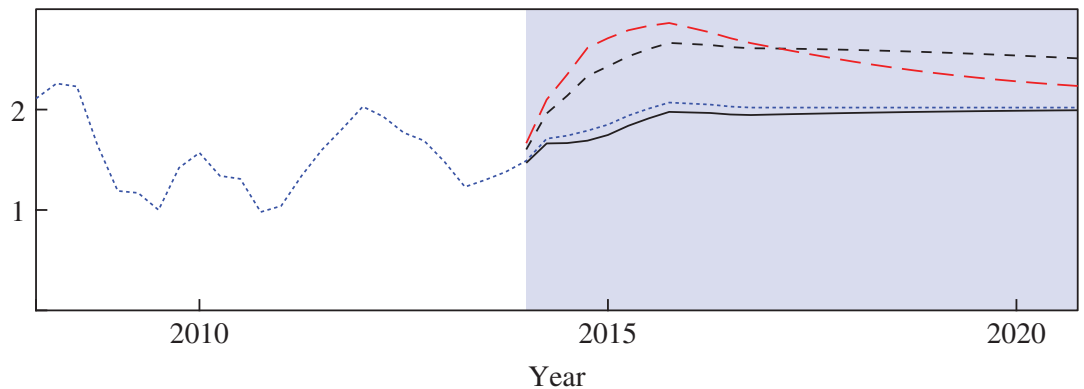

Sources: Federal Reserve Board; Lindé, Smets, and Wouters (2016); authors' calculations.

a. The shaded area is a forecast. 
to a more rapid increase in nominal interest rates in the DSGE model, as inflation rises quickly in response to the credible commitment to pursue inflation above 2 percent under the risk adjustment strategy. All told, the stimulus associated with the risk adjustment strategy leads to inflation of between 2 and $2^{1 / 2}$ percent after 2015 in both models.

The change rule with shadow rate adjustment commits to not raising the federal funds rate until the cumulated shortfall in inflation and output from their objectives from 2014 onward is unwound. In the FRB/US model, this commitment leads to a considerably longer period during which the nominal interest rate is at its ELB, with the output gap rising to above 2 percent and inflation near $2 \frac{1}{2}$ percent by the late 2010s. In the DSGE model, activity and inflation jump immediately, and the path for the nominal federal funds rate is little different from the consensus outlook.

The overshooting that attends the risk adjustment and commitment strategies raises possible areas of concern. One is whether the shifts in expectations and consequent changes in economic performance associated with the alternative rules would be realized: The shifts depend on the idea that the model's equations fairly capture structural relationships and that expectations formation would shift in the manner predicted by the models. In particular, the benefits of temporary overshooting rely on forward-looking behavior that may not be a good representation of actual behavior (McKay, Nakamura, and Steinsson 2016; Gabaix 2016; Kiley 2016). It is reasonable, to say the least, to entertain the possibility that such shifts would not occur, as the sharp jump in activity and inflation shown under the commitment strategy in figure 11 highlight. This criticism applies to the entirety of the exercises we have considered and the overwhelming majority of related research. Notably, it also applies to proposals to increase the inflation target.

\section{Summary and Conclusions}

Nominal interest rates may remain substantially below the averages of the last half century, because central banks' inflation objectives lie below the average level of inflation and because estimates of the real interest rate likely to prevail over the long run fall notably short of the average real interest rate experienced during this period. According to simulations using a recent-generation DSGE model and the FRB/US model, monetary policy strategies based on traditional simple policy rules lead to poor economic performance when the equilibrium real interest rate is as low as 1 percent, with the ELB binding between one-third and two-fifths of the time, and 
both inflation and economic activity falling systematically short of desirable levels. The frequency with which the ELB binds is estimated to be significantly higher than in previous analyses.

A risk adjustment to a traditional simple rule-whereby monetary policymakers are more accommodative, on average, than prescribed by the unadjusted rule-ensures that inflation averages its 2 percent objective-and requires that policymakers systematically seek inflation near 3 percent when the ELB is not binding. Nonetheless, such an approach only moderately improves the average level and stability of economic activity.

Commitment strategies whereby monetary accommodation is not removed until either inflation or economic activity overshoots its longrun objective are very effective in both the DSGE and FRB/US models. Although the commitment strategies we examine implicitly include thresholds for inflation and real activity to determine the exit from the ELB, we find that such thresholds are insufficient to achieve the full gains from commitments in the models we analyze. Rather, such a policy must be combined with additional commitments to make up forgone accommodation. In particular, we find that under a shadow rate policy — whereby the federal funds rate is not allowed to rise above the ELB until the shadow rate has returned to the ELB - the effects of the ELB are essentially eliminated.

We also illustrated issues that arise when considering the inflation target's desirable level. As we emphasized, the degree to which such a shift could improve economic outcomes depends on the costs of steady-state inflation versus those associated with the ELB. The costs associated with the ELB depend, in turn, on the potential credibility of commitment policies: If commitments to overshoot can be made credibly, the costs associated with the ELB shrink dramatically. The current state of our knowledge of these dimensions is limited. Although we view our analysis as a useful illustration of the issues involved, further work is clearly needed in this area.

There are a number of limitations to our analysis. Perhaps most important, other policy strategies and different analytical approaches could lead to different conclusions. As we noted at the beginning of this paper, QE has been deployed to address ELB concerns across the advanced economies: Although some research points to clear benefits from such actions (Reifschneider 2016), a more in-depth analysis involving stochastic simulations and a comparison with commitment approaches has not been performed, and some models suggest less efficacy than others. In addition, a complementary approach would look at historical parallels. The experience of Japan in recent decades and of Europe earlier this decade may highlight 
possible dangers of approaches that underweight the asymmetry in risks associated with the ELB and do not maintain accommodation until inflation rises above its target. Conversely, the factors that led to the Great Inflation of the 1970s-and in particular the root causes of an unanchoring of inflation expectations-are likely not well captured by our models, which assume that agents believe inflation will eventually revert to a central bank's target. Analysis of these issues with a model-based framework and how they interact with the ELB will require both new models and investigations of computational and related solution issues that arise from the ELB and other important nonlinearities.

ACKNOWLEDGMENTS The authors benefited from discussions of this project at the Sveriges Riksbank and Federal Reserve Board, as well as comments and suggestions from Laurence Ball, Ben Bernanke, and James Stock. Technical assistance from and discussions with Flint Brayton and Luca Guerrieri were especially valuable. Any errors are the sole responsibility of the authors. 


\section{References}

Abel, Andrew B. 1997. "Comment on 'The Costs and Benefits of Going from Low Inflation to Price Stability." In Reducing Inflation: Motivation and Strategy, edited by Christina D. Romer and David H. Romer. University of Chicago Press.

Adam, Klaus, and Roberto M. Billi. 2006. "Optimal Monetary Policy under Commitment with a Zero Bound on Nominal Interest Rates." Journal of Money, Credit and Banking 38, no. 7: 1877-905.

Ball, Laurence M. 2014. "The Case for a Long-Run Inflation Target of Four Percent." Working Paper no. 14/92. Washington: International Monetary Fund.

Ball, Laurence M., Joseph Gagnon, Patrick Honohan, and Signe Krogstrup. 2016. "What Else Can Central Banks Do?" Geneva Report on the World Economy, no. 18. London: Centre for Economic Policy Research.

Barro, Robert J., and David B. Gordon. 1983. "Rules, Discretion and Reputation in a Model of Monetary Policy." Journal of Monetary Economics 12, no. 1: 101-21.

Bernanke, Ben S. 2005. "The Global Saving Glut and the U.S. Current Account Deficit." Remarks given at the Sandridge Lecture, Virginia Association of Economists, Richmond, March 10.

- 2015a. The Courage to Act: A Memoir of a Crisis and Its Aftermath. New York: W. W. Norton.

- 2015b. "The Taylor Rule: A Benchmark for Monetary Policy?" Ben Bernanke's Blog, April 28. Brookings Institution, Washington.

Billi, Roberto M. 2011. "Output Gaps and Monetary Policy at Low Interest Rates." Economic Review (Federal Reserve Bank of Kansas City), no. 1: 5-29.

Blanchard, Olivier, Giovanni Dell'Ariccia, and Paolo Mauro. 2010. "Rethinking Macroeconomic Policy." Staff Position Note no. 10/03. Washington: International Monetary Fund.

Boivin, Jean, Michael T. Kiley, and Frederic S. Mishkin. 2010. "How Has the Monetary Transmission Mechanism Evolved over Time?" In Handbook of Monetary Economics, Volume 3A, edited by Benjamin M. Friedman and Michael Woodford. Amsterdam: North-Holland.

Brayton, Flint, Thomas Laubach, and David Reifschneider. 2014. "The FRB/US Model: A Tool for Macroeconomic Policy Analysis.” FEDS Notes. Washington: Board of Governors of the Federal Reserve System.

Calvo, Guillermo A. 1983. "Staggering Prices in a Utility-Maximizing Framework." Journal of Monetary Economics 12, no. 3: 383-98.

Campbell, Jeffrey R., Charles L. Evans, Jonas D. M. Fisher, and Alejandro Justiniano. 2012. "Macroeconomic Effects of Federal Reserve Forward Guidance." Brookings Papers on Economic Activity, Spring. 1-54.

Christoffel, Kai, Günter Coenen, and Anders Warne. 2008. "The New Area-Wide Model of the Euro Area: A Micro-Founded Open-Economy Model for Forecasting and Policy Analysis." Working Paper no. 944. European Central Bank.

Chung, Hess, Edward Herbst, and Michael T. Kiley. 2015. "Effective Monetary Policy Strategies in New Keynesian Models: A Reexamination." NBER Macroeconomics Annual 29: 289-344. 
Chung, Hess T., Michael T. Kiley, and Jean-Philippe Laforte. 2010. "Documentation of the Estimated, Dynamics, Optimization-based (EDO) Model of the U.S. Economy: 2010 Version." Finance and Economics Discussion Series no. 2010-29. Washington: Board of Governors of the Federal Reserve System.

Chung, Hess, Jean-Philippe Laforte, David Reifschneider, and John C. Williams. 2012. "Have We Underestimated the Likelihood and Severity of Zero Lower Bound Events?" Journal of Money, Credit and Banking 44, suppl. 1: 47-82.

Coenen, Günter, Athanasios Orphanides, and Volker Wieland. 2004. "Price Stability and Monetary Policy Effectiveness When Nominal Interest Rates Are Bounded at Zero." Advances in Macroeconomics 4, no. 1: article 1.

Coibion, Olivier, Yuriy Gorodnichenko, and Johannes Wieland. 2012. "The Optimal Inflation Rate in New Keynesian Models: Should Central Banks Raise Their Inflation Targets in Light of the Zero Lower Bound?" Review of Economic Studies 79, no. 4: 1371-406.

Del Negro, Marco, Domenico Giannone, Marc P. Giannoni, and Andrea Tambalotti. 2017. "Safety, Liquidity, and the Natural Rate of Interest." In the present volume of Brookings Papers on Economic Activity.

Edge, Rochelle M., Michael T. Kiley, and Jean-Philippe Laforte. 2008. "Natural Rate Measures in an Estimated DSGE Model of the U.S. Economy." Journal of Economic Dynamics and Control 32, no. 8: 2512-35.

Eggertsson, Gauti B., and Michael Woodford. 2003. "The Zero Bound on Interest Rates and Optimal Monetary Policy." Brookings Papers on Economic Activity, no. 1: 139-211.

Eggertsson, Gauti B., Neil R. Mehrotra, and Jacob A. Robbins. 2017. "A Model of Secular Stagnation: Theory and Quantitative Evaluation." Working Paper no. 23093. Cambridge, Mass.: National Bureau of Economic Research.

Engen, Eric M., Thomas Laubach, and David Reifschneider. 2015. "The Macroeconomic Effects of the Federal Reserve's Unconventional Monetary Policies." Finance and Economics Discussion Series no. 2015-005. Washington: Board of Governors of the Federal Reserve System.

Erceg, Christopher J., Luca Guerrieri, and Christopher Gust. 2005. "SIGMA: A New Open Economy Model for Policy Analysis." International Finance Discussion Paper no. 835. Washington: Board of Governors of the Federal Reserve System.

Evans, Charles, Jonas Fisher, François Gourio, and Spencer Krane. 2015. "Risk Management for Monetary Policy Near the Zero Lower Bound." Brookings Papers on Economic Activity, Spring: 141-96.

Feldstein, Martin S. 1997. "The Costs and Benefits of Going from Low Inflation to Price Stability." In Reducing Inflation: Motivation and Strategy, edited by Christina D. Romer and David H. Romer. University of Chicago Press.

Fischer, Stanley. 1981. "Towards an Understanding of the Costs of Inflation: II." Carnegie-Rochester Conference Series on Public Policy 15: 5-41.

Friedman, Milton. 1969. The Optimum Quantity of Money and Other Essays. London: Aldine.

Fuhrer, Jeffrey C., and George R. Moore. 1995. "Monetary Policy Trade-Offs and the Correlation between Nominal Interest Rates and Real Output." American Economic Review 85, no. 1: 219-39. 
Gabaix, Xavier. 2016. “A Behavioral New Keynesian Model.” Working Paper no. 22954. Cambridge, Mass.: National Bureau of Economic Research.

Gagnon, Etienne, Benjamin K. Johannsen, and David Lopez-Salido. 2016. "Understanding the New Normal: The Role of Demographics." Finance and Economics Discussion Series no. 2016-080. Washington: Board of Governors of the Federal Reserve System.

Guerrieri, Luca, and Matteo Iacoviello. 2015. "OccBin: A Toolkit for Solving Dynamic Models with Occasionally Binding Constraints Easily." Journal of Monetary Economics 70: 22-38.

Hamilton, James D., Ethan S. Harris, Jan Hatzius, and Kenneth D. West. 2015. "The Equilibrium Real Funds Rate: Past, Present and Future." Working Paper no. 21476. Cambridge, Mass.: National Bureau of Economic Research.

Holston, Kathryn, Thomas Laubach, and John C. Williams. 2017. "Measuring the Natural Rate of Interest: International Trends and Determinants." Journal of International Economics, forthcoming.

Kiley, Michael T. 2002. "Partial Adjustment and Staggered Price Setting." Journal of Money, Credit and Banking 34, no. 2: 283-98.

_. 2014. "The Aggregate Demand Effects of Short- and Long-Term Interest Rates." International Journal of Central Banking 10, no. 4: 69-104.

. 2015. "What Can the Data Tell Us about the Equilibrium Real Interest Rate?" Finance and Economics Discussion Series no. 2015-77. Washington: Board of Governors of the Federal Reserve System.

2016. "Policy Paradoxes in the New Keynesian Model." Review of Economic Dynamics 21: 1-15.

_. 2017. "The Power of Interest-Rate Forward Guidance When Households and Businesses Are Not Very Forward-Looking." Working paper. https://www. dropbox.com/s/3fx8s2kkc47y1bh/frbcommit.pdf?dl=0

Kiley, Michael T., Eileen Mauskopf, and David Wilcox. 2007. "Issues Pertaining to the Specification of a Numerical Price-Related Objective for Monetary Policy." Federal Open Market Committee memo, March 12. https://www.federalreserve. gov/monetarypolicy/files/FOMC20070312memo01.pdf

Laforte, Jean-Philippe, and John Roberts. 2014. "November 2014 Update of the FRB/US Model.” FEDS Notes. Washington: Board of Governors of the Federal Reserve System.

Laubach, Thomas, and John C. Williams. 2003. "Measuring the Natural Rate of Interest." Review of Economics and Statistics 85, no. 4: 1063-70.

—. 2016. "Measuring the Natural Rate of Interest Redux." Business Economics 51, no. 2: 57-67.

Lindé, Jesper, Frank Smets, and Rafael Wouters. 2016. "Challenges for Central Banks' Macro Models.” In Handbook of Macroeconomics, Volume 2, edited by John B. Taylor and Harald Uhlig. Amsterdam: North-Holland.

McKay, Alisdair, Emi Nakamura, and Jón Steinsson. 2016. "The Power of Forward Guidance Revisited.” American Economic Review 106, no. 10: 3133-58. 
Nakamura, Emi, Jón Steinsson, Patrick Sun, and Daniel Villar. 2016. "The Elusive Costs of Inflation: Price Dispersion during the U.S. Great Inflation.” Working Paper no. 22505. Cambridge, Mass.: National Bureau of Economic Research.

Nakata, Taisuke. 2014. "Reputation and Liquidity Traps." Finance and Economics Discussion Series no. 2014-50. Washington: Board of Governors of the Federal Reserve System.

Nakata, Taisuke, and Sebastian Schmidt. 2016. "The Risk-Adjusted Monetary Policy Rule." Finance and Economics Discussion Series no. 2016-061. Washington: Board of Governors of the Federal Reserve System.

Orphanides, Athanasios, and Volker Wieland. 1998. "Price Stability and Monetary Policy Effectiveness When Nominal Interest Rates Are Bounded at Zero." Finance and Economics Discussion Series no. 1998-35. Washington: Board of Governors of the Federal Reserve System.

Ravn, Morten O., and Vincent Sterk. 2017. "Macroeconomic Fluctuations with HANK and SAM: An Analytical Approach." Working paper. http://www. homepages.ucl.ac.uk/ uctpvst/HANK\&SAM_analytical.pdf

Reifschneider, David. 2016. "Gauging the Ability of the FOMC to Respond to Future Recessions." Finance and Economics Discussion Series no. 2016-068. Washington: Board of Governors of the Federal Reserve System.

Reifschneider, David L., and John M. Roberts. 2006. "Expectations Formation and the Effectiveness of Strategies for Limiting the Consequences of the Zero Bound." Journal of the Japanese and International Economies 20, no. 3: 314-37.

Reifschneider, David, and John C. Williams. 2000. "Three Lessons for Monetary Policy in a Low-Inflation Era." Journal of Money, Credit and Banking 32, no. 4, pt. 2: 936-66.

Schmitt-Grohé, Stephanie, and Martin Uribe. 2010. "The Optimal Rate of Inflation." In Handbook of Monetary Economics, Volume 3B, edited by Benjamin M. Friedman and Michael Woodford. Amsterdam: North-Holland.

Smets, Frank, and Rafael Wouters. 2007. "Shocks and Frictions in US Business Cycles: A Bayesian DSGE Approach.” American Economic Review 97, no. 3: 586-606.

Summers, Lawrence. 1991. "How Should Long-Term Monetary Policy Be Determined?" Journal of Money, Credit and Banking 23, no. 3, pt. 2: 625-31.

Svensson, Lars E. O. 2010. "Inflation Targeting." In Handbook of Monetary Economics, Volume 3B, edited by Benjamin M. Friedman and Michael Woodford. Amsterdam: North-Holland.

Taylor, John B. 1993. "Discretion versus Policy Rules in Practice." CarnegieRochester Conference Series on Public Policy 39: 195-214.

1999. "Introduction.” In Monetary Policy Rules, edited by John B. Taylor. University of Chicago Press.

Taylor, John B., and John C. Williams. 2010. "Simple and Robust Rules for Monetary Policy." In Handbook of Monetary Economics, Volume 3B, edited by Benjamin M. Friedman and Michael Woodford. Amsterdam: North-Holland. 
Williams, John C. 2003. "Simple Rules for Monetary Policy." Economic Review (Federal Reserve Bank of San Francisco): 1-12.

_. 2009. "Heeding Daedalus: Optimal Inflation and the Zero Lower Bound." Brookings Papers on Economic Activity, Fall: 1-37.

Wolman, Alexander L. 1998. "Staggered Price Setting and the Zero Bound on Nominal Interest Rates.” Economic Quarterly 84, no. 4: 1-24.

Woodford, Michael. 1999. "Optimal Monetary Policy Inertia.” Manchester School 67, suppl. 1: 1-35.

- 2003. Interest and Prices: Foundations of a Theory of Monetary Policy. Princeton University Press.

Yellen, Janet L. 2012. "Perspectives on Monetary Policy." Speech given at the Boston Economic Club Dinner, Boston, June 6.

2017. "The Economic Outlook and the Conduct of Monetary Policy." Speech given at the Stanford Institute for Economic Policy Research, Stanford, Calif., January 19. 


\section{Comments and Discussion}

\section{COMMENT BY}

LAURENCE BALL This paper is an important warning to the Federal Reserve. Michael Kiley and John Roberts simulate leading macroeconomic models, including the Fed's own forecasting model, assuming that the Fed maintains its current inflation target of 2 percent. Kiley and Roberts find that the effective lower bound (ELB) on interest rates will greatly constrain future monetary policy. The economy will spend a large fraction of the time-perhaps 30 or 40 percent - with interest rates at the ELB, and this outcome will reduce the average level of output by 1 or 2 percent.

Motivated by these findings, Kiley and Roberts consider policy proposals that might mitigate the ELB problem. These proposals include an increase in the Fed's inflation target, and a "commitment strategy" in which output and inflation overshoot their long-run levels after an ELB episode. Kiley and Roberts analyze the costs and benefits of these strategies and call for more research.

In this comment, I present three exercises that extend and complement Kiley and Roberts's analysis:

-A calculation that reinforces Kiley and Roberts's conclusion about the risk of hitting the ELB.

-An extension of Kiley and Roberts's analysis of the optimal inflation target. I account for microeconomic distortions that reduce output below the optimal level, which strengthens the case for a higher target.

-An analysis of output and inflation overshoots under the commitment strategy that Kiley and Roberts suggest. The results leave me dubious that such a strategy would solve the ELB problem. 
THE RISK OF HITTING THE ELB Kiley and Roberts derive their results from complex models. Yet their central point—-the high risk of hitting the ELBcan be seen more simply. ${ }^{1}$

Following Kiley and Roberts, assume that the Fed follows Janet Yellen's "balanced" version of the Taylor rule. This rule (Kiley and Roberts's equation 2) is

$$
i=r^{*}+\pi^{*}+(1.5)\left(\pi-\pi^{*}\right)+y
$$

where $i$ is the nominal interest rate, $\pi$ is inflation, $y$ is the output gap, $r^{*}$ is the neutral real interest rate, and $\pi^{*}$ is the inflation target.

Also, following Kiley and Roberts, assume the inflation target $\pi^{*}$ is 2.0 and the neutral rate $r^{*}$ is 1.0. With these parameters, the Taylor rule simplifies to

$$
i=(1.5) \pi+y \text {. }
$$

We need one other assumption for my exercise: an equation for inflation. Assume a simple Phillips curve with anchored expectations:

$$
\pi=2+(0.25) y \text {. }
$$

Inflation equals the Fed's 2 percent target in the long run, but it fluctuates in response to output movements. A 1 percent rise in output raises inflation by 0.25 percentage point, which is consistent with recent empirical work (Ball 2015; Blanchard 2016).

Substituting the Phillips curve into Kiley and Roberts's Taylor rule yields

$$
i=3+(1.375) y \text {. }
$$

An increase in output raises the interest rate because output appears in the Taylor rule, and also because inflation rises and inflation appears in the rule.

Assume that the ELB on the interest rate is zero. Under what conditions will the ELB bind? We can answer that question by setting $i=0$ in the last equation and solving for $\mathrm{y}$ :

$$
y=-3 \div 1.375=-2.2 \text {. }
$$

The ELB binds if output falls 2.2 percent below potential.

1. This section of my comment draws on Ball and others (2016). 
An output gap of -2.2 is a modest downturn in the economy. Assuming a textbook Okun's law, this gap means that unemployment exceeds its natural rate by $0.5 \times 2.2=1.1$ percentage points. In the eight recessions since 1960 , unemployment has risen more than 1.1 percentage points above the natural rate in seven cases, including the mild recession of 2001 (based on natural rate estimates from the Congressional Budget Office).

Therefore, a Great Recession like that of 2008-09 is not necessary for the ELB to constrain policy. If future recessions are similar in magnitude to past recessions, they will cause interest rates to hit zero far more often than not. If recessions continue to occur with the same frequency as those since 1960 - about once every seven years, on average — the economy will spend much time at the ELB.

THE OPTIMAL INFLATION TARGET One way to mitigate the ELB problem is to raise the Fed's inflation target above the current level of 2 percent. That would raise the steady-state nominal interest rate, giving policymakers more room to cut rates in a downturn. Yet many economists oppose a higher inflation target, believing that inflation is too costly.

Kiley and Roberts derive optimal inflation targets in their two models, using three versions of a loss function that depends on inflation and the output gap. Assuming a neutral real rate of 1 percent, the optimal inflation targets range from about 2 to 4 percent, as shown in Kiley and Roberts's figure 10 .

Here, I focus on Kiley and Roberts's results for the FRB/US model, assuming a loss function with equal weights on the squared deviations of inflation and output from their optimal levels:

$$
\operatorname{Loss}=E\left[\left(\pi-\pi^{0}\right)^{2}+\left(y-y^{0}\right)^{2}\right]
$$

where $\pi^{0}$ and $y^{0}$ are the optimal inflation rate and output gap, respectively. I assume $\pi^{0}=2.0$. These assumptions underlie the upper-middle panel of Kiley and Roberts's figure 10, in which the optimal inflation target is about 3 percent when $r^{*}=1$.

My variation on Kiley and Roberts's analysis concerns the optimal output gap, $y^{0}$. The output gap is the difference between output and potential output, where potential is average output in the absence of the ELB. Kiley and Roberts assume that the optimal gap $y^{0}$ is zero. Equivalently, if the ELB never binds, then the average level of output is optimal.

This assumption is debatable, as Kiley and Roberts note. Many economists argue that average output is less than optimal output because of microeconomic distortions, such as imperfect competition, taxes, and asymmetric 
Table 1. Loss Components for Alternative Inflation Targets

\begin{tabular}{lccc}
\hline & $\pi^{*}=2$ & $\pi^{*}=3$ & $\pi^{*}=4$ \\
\hline $\operatorname{Var}(\pi)$ & 2.0 & 1.8 & 1.6 \\
$(E[\pi]-2)^{2}$ & 0.0 & 1.0 & 4.0 \\
$\operatorname{Var}(y)$ & 8.5 & 6.9 & 5.9 \\
$(E[y]-0)^{2}$ & 0.5 & 0.1 & 0.0 \\
$(E[y]-5)^{2}$ & 32.5 & 28.1 & 25.0 \\
Total loss & & & \\
$\quad$ if $y^{0}=0$ & 11.0 & 9.8 & 11.5 \\
if $y^{0}=5$ & 43.0 & 37.8 & 36.5 \\
\hline
\end{tabular}

Source: Author's calculations.

information in the labor market. This idea is, for example, a key assumption in Finn Kydland and Edward Prescott's (1977) theory of dynamic inconsistency in monetary policy. If average output is suboptimal, even without the ELB, then the optimal gap $y^{0}$ is positive.

This point matters because lowering the inflation target, by making the ELB more binding, pushes the average output gap below zero. This effect implies only a second-order welfare loss if the optimal gap is zero, but a first-order loss if the optimal gap is positive. A first-order loss strengthens the case against a low inflation target.

To see this point formally, decompose the social loss function as follows:

$$
E\left[\left(\pi-\pi^{0}\right)^{2}+\left(y-y^{0}\right)^{2}\right]=\operatorname{Var}(\pi)+\left(E[\pi]-\pi^{0}\right)^{2}+\operatorname{Var}(y)+\left(E[y]-y^{0}\right)^{2},
$$

where $E[y]$ is the average output gap. Notice that

$$
\frac{d(\text { Loss })}{d(E[y])}=2\left(E[y]-y^{0}\right)=-2 y^{0} \text { at } E[y]=0 .
$$

When a low inflation target reduces $E[y]$ below zero, the first-order effect on the loss is $2 y^{0}$. This effect is zero if $y^{0}=0$ but positive if $y^{0}>0$.

To gauge the quantitative importance of this point, I revisit the analysis of the upper-middle panel of Kiley and Roberts's figure 10. I make the same assumptions as Kiley and Roberts, except $y^{0}=5.0$ : optimal output exceeds average output by 5 percent. I view this calibration as plausible, although admittedly there is little hard evidence on the value of $y^{0}$.

My table 1 shows the four components of the loss function, and the total loss, for alternative inflation targets. I present results for $y^{0}=0$ and for $y^{0}=5$, which imply different values of $\left(E[y]-y^{0}\right)^{2}$. For $y^{0}=0$, the total 
loss is smaller with a 3 percent target than with 2 or 4 percent, confirming the result in Kiley and Roberts's figure 10 that the optimal target is about 3 percent. For $y^{0}=5$, by contrast, the loss is smallest with a 4 percent target. Accounting for a positive $y^{0}$ strengthens the case for a higher inflation target. ${ }^{2}$

SHADOW RATE COMMITMENT STRATEGIES Can policymakers mitigate the ELB problem without raising the inflation target? They can in Kiley and Roberts's models, by committing to allow output and inflation to overshoot their long-run levels after an ELB episode. Kiley and Roberts find that one version of this strategy, based on a "shadow interest rate," effectively eliminates the ELB problem.

As Kiley and Roberts acknowledge, this strategy is dynamically inconsistent. During an ELB episode, the expectation of overshoots helps the economy recover; but after a recovery, policymakers would like to raise interest rates and choke off the overshoots. The key questions about the strategy, therefore, concern credibility. Will policymakers keep their commitment to overshoots? Will people believe that policymakers will keep their commitment?

The answers probably depend on the magnitudes of the necessary overshoots. For example, if the Fed's long-run inflation target is 2 percent, people may believe that policymakers will let inflation rise temporarily to 2.5 percent, but not to 10 percent. Kiley and Roberts do not quantify the overshoots implied by the shadow rate strategy, so I seek to do so.

Shadow rate policy. The shadow interest rate evolves over the course of an ELB episode. It equals the cumulated interest rate changes that are dictated by a simple policy rule, but do not occur because rates are stuck at the ELB. In each quarter, the forgone interest rate change is proportional to a variable that I call $x$ :

$$
x=y+(\pi-2) .
$$

The variable $x$ is the sum of the output gap and the deviation of inflation from 2 percent.

Because each forgone interest rate change is proportional to $x$, the shadow interest rate is proportional to the cumulation of $x$ since the beginning of the ELB episode. I denote this cumulation by $\Sigma x$. Under a shadow rate

2. The numbers in the table are calculated from the means and variances of inflation and output, which Kiley and Roberts provided to me. 
commitment strategy, the Fed keeps interest rates at the ELB until the shadow rate becomes positive, which happens when $\Sigma x$ becomes positive. ${ }^{3}$

When an ELB episode begins, $x$ is less than zero, typically because both $y$ and $\pi-2$ are negative. As long as $x$ remains below zero, its cumulation $\sum x$ becomes increasingly negative over time. When the economy recovers and $x$ becomes positive, that does not trigger an immediate increase in the interest rate. Rates must stay at the ELB until a series of positive $x$ s brings $\sum x$ up above zero.

This strategy can require large overshoots of output and inflation. If a recession causes shortfalls of these variables from their long-run levels, the recession must be followed by an economic boom in which deviations from equilibrium are just as large, but positive. This overheating must be completed before the Fed raises the interest rate.

Revisiting the Great Recession. Consider the recent history of output and inflation. I measure output gaps by assuming Okun's law and a 5 percent natural rate of unemployment: $y=-2(u-5)$. I measure inflation with the core personal consumption expenditures deflator. From 2009 through 2016, $y$ cumulates to -39 percent of annual output and $\pi-2$ cumulates to -4 percentage points. Adding these numbers, $\Sigma x$ for $2009-16$ is -43 .

Assume the economy is in long-run equilibrium in 2017, with $y=0$ and $\pi=2$. Then $x=0$ in 2017 and $\Sigma x$ remains at -43 . If we start from this point, a shadow rate policy requires the Fed to keep interest rates at the ELB until $\sum x$ rises from -43 to 0 .

In analyzing the shadow rate policy, however, it is probably unfair to assume that the Great Recession was as bad as it actually was. If the policy had been in place at the start of the recession, expectations of future accommodation might have sped up the recovery of output and inflation. If so, then $\Sigma x$ would not have fallen as much, and it would not need to climb back as far.

Future researchers might use Kiley and Roberts's models to estimate the effects of a shadow rate policy on the Great Recession. For now, I simply assume that the policy would have cut output and inflation deviations in half. This means that $\Sigma x$ in 2017 would be -21.5 rather than -43 . I view this scenario as optimistic.

Simulating the overshoot. With $\Sigma x$ starting at -21.5 , how would output and inflation evolve after 2017? Again, future researchers could derive

3. See Kiley and Roberts's equations 5-7, which define the shadow rate policy. 
Table 2. Simulating a Shadow Rate Strategy

\begin{tabular}{ccccc}
\hline Year & $y$ & $\pi$ & $x$ & $\Sigma x$ \\
\hline 2017 & 0.0 & 2.0 & 0.0 & -21.5 \\
2018 & 1.2 & 2.3 & 1.5 & -20.0 \\
2019 & 2.3 & 2.6 & 2.9 & -17.1 \\
2020 & 3.5 & 2.9 & 4.4 & -12.7 \\
2021 & 4.4 & 3.1 & 5.5 & -7.2 \\
2022 & 5.1 & 3.3 & 6.4 & -0.8 \\
2023 & 5.8 & 3.5 & 7.3 & 6.5 \\
\hline
\end{tabular}

Source: Author's calculations.

answers in Kiley and Roberts's models. I use a minimalist model with two equations:

$$
\pi_{t}=2+(0.25) y_{t}
$$

and

$$
y_{t}=-(0.4)\left(i_{t-1}-\pi_{t-1}-1.0\right)+(0.8) y_{t-1},
$$

where a time period is a year. The first equation is the Phillips curve discussed above. The second is a dynamic IS curve, which is roughly equivalent to the quarterly equations given by Glenn Rudebusch and Lars Svensson (1999) and by Ball and others (2016).

I assume the ELB is zero, so I set $i=0$ in the IS equation. I simulate output and inflation with initial conditions of $y=0, \pi=2$, and $\Sigma x=-21.5$ in 2017.

My table 2 presents the results. Starting in 2018, $y$ and $\pi$ rise steadily, with the output increases more pronounced because the Phillips curve is fairly flat. A series of positive $x$ s pushes $\Sigma x$ above zero in 2023 , so the Fed can start raising interest rates in that year. The output gap in 2023 is 5.8 percent. If we again assume Okun's law and a 5 percent natural rate of unemployment, the unemployment rate in 2023 is $5-(5.8) / 2=2.1$ percent.

Is this scenario plausible? Would the Fed really keep interest rates at zero for six years while the unemployment rate falls to 2.1 percent? Would people believe that the Fed will carry out this policy?

I do not think so. In the face of large adverse shocks, the shadow rate strategy is not a realistic solution to the ELB problem. We need a higher inflation target. 


\section{REFERENCES FOR THE BALL COMMENT}

Ball, Laurence. 2015. "Comment on 'Inflation and Activity' by Olivier Blanchard, Eugenio Cerutti and Lawrence Summers.” In ECB Forum on Central Banking: Inflation and Unemployment in Europe, Conference Proceedings. European Central Bank.

Ball, Laurence M., Joseph Gagnon, Patrick Honohan, and Signe Krogstrup. 2016. "What Else Can Central Banks Do?" Geneva Report on the World Economy, no. 18. London: Centre for Economic Policy Research.

Blanchard, Olivier. 2016. "The Phillips Curve: Back to the '60s?" American Economic Review 106, no. 5: 31-34.

Kydland, Finn E., and Edward C. Prescott. 1977. "Rules Rather Than Discretion: The Inconsistency of Optimal Plans." Journal of Political Economy 85, no. 3: 473-92.

Rudebusch, Glenn D., and Lars E. O. Svensson. 1999. "Policy Rules for Inflation Targeting." In Monetary Policy Rules, edited by John B. Taylor. University of Chicago Press.

\section{COMMENT BY}

BEN BERNANKE Over the years, the Brookings Papers on Economic Activity has published a remarkably large share of the most important papers on the conduct of monetary policy when interest rates are near their zero lower bound-or, more accurately, at their "effective" lower bound (ELB), because central banks have been able to set short-term rates at modestly negative levels. The seminal papers by Paul Krugman (1998) and Gauti Eggertsson and Michael Woodford (2003) appeared in the Brookings Papers, as did papers on the zero lower bound by Ben Bernanke, Vincent Reinhart, and Brian Sack (2004); John Williams (2009); Jeffrey Campbell and others (2012); and Charles Evans and others (2015). And that does not include the closely related work of Joshua Hausman and Johannes Wieland $(2014,2015)$ on Japanese monetary policy, and Marco Del Negro and others (2017) on why the natural rate of interest appears to be so low.

Building on this tradition, this paper by Michael Kiley and John Roberts is a useful update and extension of the ELB literature. It is also timely: With the Federal Reserve apparently on a trajectory to escape the gravitational pull of the ELB, a serious discussion of whether and how the monetary policy framework should be modified to better deal with the ELB constraint in the future is certainly warranted.

My discussion is in three sections. I first comment on Kiley and Roberts's quantitative assessment of the frequency, duration, and severity of ELB episodes (by which I mean periods when the policy interest rate is at or very close to its ELB). Second, I discuss the paper's findings about the optimal 
response of monetary policymakers to the ELB constraint. Finally, I briefly turn to what I believe to be a serious, if understandable, shortcoming of both this paper and much of the literature, namely, paying insufficient attention to the communication challenges that central banks face when interest rates are close to the ELB.

On the first point, Kiley and Roberts emphasize their finding, based on model simulations, that ELB episodes are likely to be more frequent, longer, and more severe than previously believed. (They overstate a bit the extent to which earlier research downplayed the ELB threat, I think, but it is true that some earlier papers characterized the risks associated with the ELB as likely to be manageable, at least in the U.S. context.) Although, in principle, many factors could influence the frequency and severity of ELB episodes, for Kiley and Roberts the most important reason for increased concern about the ELB is the secular decline in the equilibrium nominal interest rate, from about 6 percent in the precrisis era to about 3 percent today. Why interest rates have declined so much, and whether the decline is permanent, are contentious questions; Del Negro and others (2017) discuss the evidence in more detail. What is clear is that the lower the "normal" level of interest rates, the less space exists for the central bank to cut rates to mitigate an economic downturn.

Kiley and Roberts appropriately emphasize that the frequency and severity of ELB episodes are not exogenous features of the economic environment but instead are endogenous and jointly determined with the monetary (and fiscal) policy regimes. In other words, statements about the risks of the ELB must be conditional on the type of policy being assumed. In this context, Kiley and Roberts show that some "standard" monetary policy rules can lead to very poor results when the equilibrium nominal interest rate is 3 percent or lower. For example, they find that a rule estimated to mimic the Fed's historical behavior, when incorporated into simulations of the FRB/ US model (the Fed's main policy model), implies that the economy will be at the ELB 32 percent of the time, that output will average 1.3 percent below potential, and that inflation will average only 1.2 percent (compared with an official inflation target of 2 percent). Alternatively, if monetary policy is assumed to follow a simple Taylor-type rule (which relates settings of the federal funds rate to inflation and the output gap), the FRB/US simulations show the economy at the ELB 38 percent of the time, with output averaging 1.1 percent below potential, and inflation averaging 1.2 percent.

These results are more adverse than those found by some earlier researchers using similar methods. Kiley and Roberts usefully explore the reasons for the differences in findings with one such paper by Williams (2009). They 
find that much of the discrepancy arises from assumptions that Williams made about how monetary policy would react to extreme outcomes. For example, in his simulations Williams apparently augmented the baseline policy rule by assuming that the Fed would provide extra accommodation if output fell 5 percent below potential for two years or more. This assumption limits the effect on the model economy of extreme events. Even in a simulation in which such an event did not occur, the assumption would matter because of its presumed effect on the economic and policy expectations of agents in the model; if agents expect policy to protect them from the most extreme outcomes, they will be more optimistic and more willing to spend in all states of the world.

How realistic is Kiley and Roberts's finding that the economy could be at the ELB more than 30 percent of the time in the future? A specific prediction of their analysis - that in the future frequent contact with the ELB will keep inflation well below the Fed's 2 percent target—can be compared with the expectations of market participants and of professional forecasters. These comparisons suggest that Kiley and Roberts's worst-case scenarios, though certainly not impossible, are not widely expected. For example, measures of inflation expectations based on comparing returns to inflationadjusted and ordinary Treasury securities suggest that market participants see inflation remaining close to the 2 percent target in the long run. ${ }^{1}$ The prices of derivatives that depend on long-run inflation outcomes also imply that market expectations of inflation are close to 2 percent. To illustrate the latter point, my figure 1 shows inflation expectations as derived from zerocoupon inflation swaps. ${ }^{2}$

My figure 1 suggests that market participants expect inflation to average about 2.25 percent over long horizons, up to 30 years. These expectations relate to inflation as measured by the consumer price index, which tends to be a bit higher than inflation measured by the index for personal consumption expenditures (the inflation rate targeted by the Fed). So my figure 1 seems quite consistent with a market expectation of 2 percent for the Fed's targeted inflation rate over very long horizons.

1. As of this writing, the inflation breakevens for 10-year-, 30-year-, and 5-year-forward horizons are all about 2 percent, according to Federal Reserve Economic Data (FRED). From 2009 through 2014, these breakevens remained above 2 percent, at levels comparable to the period before the crisis. Breakevens fell below 2 percent in 2015-16, but most commentary attributes that drop to declines in inflation risk premiums rather than lower inflation expectations; see Abrahams and others (2015) for a discussion.

2. See Fleming and Sporn (2013) for an explanation of these instruments and a discussion of their properties. 
Figure 1. Inflation Expectations Derived from Zero-Coupon Inflation Swaps

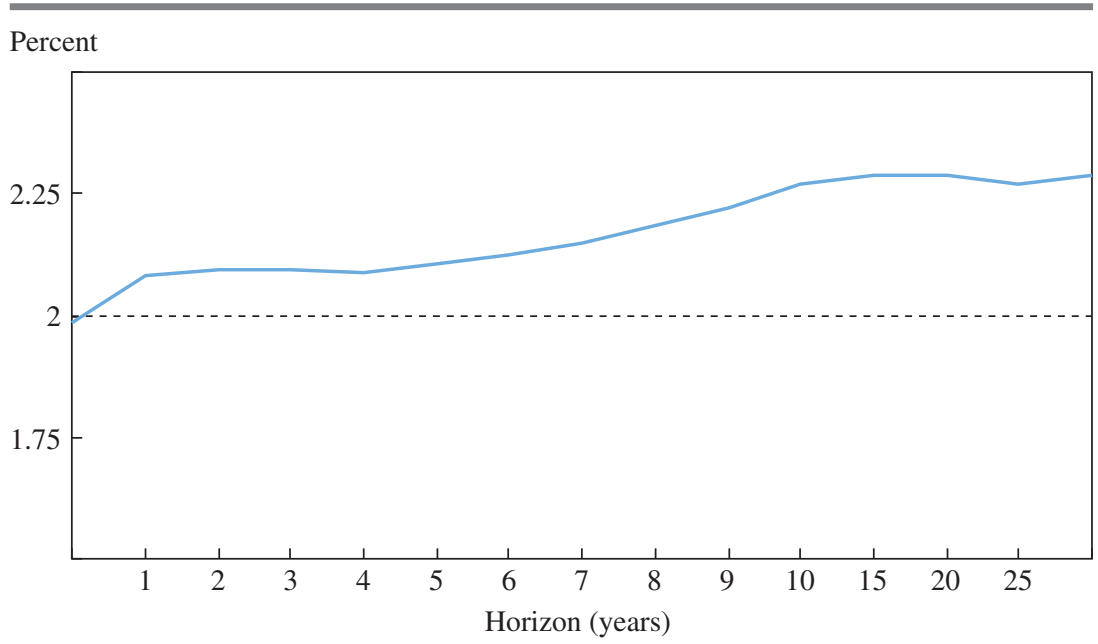

Source: Bloomberg.

Professional forecasters also see long-run inflation close to the Fed's target. For example, the Survey of Professional Forecasters (2017) projects that the inflation rate targeted by the Fed will average 2.00 percent over the period 2016-25, precisely equal to the target. Similarly, the Survey of Primary Dealers (2017) sees the inflation rate targeted by the Fed equaling 2.00 percent in the "longer run." This same group also sees inflation based on the consumer price index of close to 2.25 percent during the next five years and during the five years after that, consistent with the inflation swaps data (my figure 1) and with the Fed's preferred inflation measure remaining close to 2 percent. Interestingly, these respondents do not see the ELB as irrelevant to policy; at the median, they see a 20 percent chance that the United States will be back at the zero lower bound by 2019 .

That longer-term inflation expectations appear relatively well anchored at 2 percent appears inconsistent with the prediction that the economy will be at the ELB more than 30 percent of the time in the future, preventing the Fed from reaching its inflation target during those times. How can this contradiction be resolved? One possibility is that financial market participants and forecasters expect a high frequency of ELB episodes, but also expect the Fed to shoot for inflation well above 2 percent during times when the ELB is not binding —indeed, this is the policy of "risk-adjusting" the inflation target analyzed by Kiley and Roberts. However, although policymakers at the Fed 
may be willing to allow inflation to exceed the 2 percent target modestly and temporarily, consistent with the symmetry of the inflation target, they have given no indication that they will tolerate a sustained overshoot.

The more reasonable resolution of this puzzle is that, correctly or not, financial market participants and forecasters expect that the Fed and (perhaps) fiscal policymakers will act with sufficient force to overcome most of the economic effect of future encounters with the ELB, perhaps by using policies not considered in Kiley and Roberts's simulations, including quantitative easing and forward guidance. In this respect, perhaps the modeling approach of Williams (2009), which assumes that extraordinary policies will be used in extreme situations, better captures private sector expectations. Consistent with the view that appropriate policies can substantially overcome the effects of the ELB, inflation fell only moderately during the recent episode and, although the Great Recession was deep, the pace of decline in the unemployment rate was similar to earlier recessions, as documented by John Fernald and others (2017). This is certainly not to say that the ELB is not a problem, or that a serious rethinking of the monetary policy framework in light of the recent experience is not justified. But it appears that, at least for now, private agents believe that the Fed and the fiscal authorities will "do what it takes" to limit the frequency and severity of ELB episodes in the future.

Other than so-called unconventional policies such as quantitative easing, what policies could the Fed apply to satisfy these expectations? The basic insight from the literature-due originally to Krugman (1998), Eggertsson and Woodford (2003), and others-is that the adverse effects of the ELB are minimized when the central bank can credibly promise to keep policy rates low well after the economy leaves the ELB, with the length of the expected "make-up" period increasing with the length and severity of the ELB episode. As I explain below, Kiley and Roberts's simulations largely confirm this insight.

Kiley and Roberts use their simulation approach to consider in some detail two classes of policies designed to address the ELB constraint. First, they consider the strategy of raising the inflation target, say to 3 or 4 percent, with the goal of raising the equilibrium nominal interest rate and thus expanding the central bank's scope for rate cuts when needed. Alternatively, they also consider a policy of risk-adjusting the inflation target, meaning in practice that the Fed would shoot for inflation above 2 percent when the ELB was not binding, with the goal of keeping long-run inflation (averaged over ELB and non-ELB periods) at the current target of 2 percent. Although they are framed differently, the two policies are quali- 
tatively very similar, in that both involve the Fed pushing for higher inflation when feasible (that is, when the ELB does not bind).

Second, Kiley and Roberts also consider variants of what they call "shadow rate" policies. In their favored version, they imagine that the central bank calculates a shadow short-term interest rate, which responds slowly to inflation and the output gap. ${ }^{3}$ It is particularly important that this hypothetical shadow rate is allowed to be negative. The actual policy rate is assumed to be set equal to the shadow rate when it is above the ELB; otherwise, the actual rate is set at the ELB. Because the shadow rate adjusts slowly, when a severe ELB episode forces the shadow rate well below zero, it tends to stay there for a long time, with the result that the actual policy rate also remains at zero (or the ELB) for an extended period-a sort of lower-forlonger commitment by the central bank, with the extent of that commitment depending on the severity of the ELB episode.

The comparison of these two classes of policies amounts to a quantitative exploration of the Krugman-Eggertsson-Woodford (KEW) principle described above, that the optimal policy involves promising to keep rates low for long after an ELB episode. In the KEW framework, raising the inflation target (or risk-adjusting it) is not an efficient policy, for at least two reasons: First, as Woodford (2009) has argued, the efficient policy involves only temporarily higher inflation (in the period following the ELB episode), whereas a higher inflation target imposes the costs of higher inflation on society at all times. Second, the optimal policy is sensitive to the length and depth of the ELB episode, whereas a higher (fixed) inflation target does not necessarily lead to greater accommodation following a long period at the ELB.

In contrast, Kiley and Roberts show that their favored shadow rate policy eliminates all or nearly all the costs of the ELB, for standard KEW reasons. In particular, following the KEW principle, the shadow rate policy is a makeup policy, with the feature that a severe ELB episode triggers a long period of low policy rates, which in turn induces a temporary overshoot of output and inflation. Private agents' anticipation of this policy leads to lower longterm rates and greater economic optimism during the ELB episode itself, which largely eliminates any adverse effects in the models that Kiley and Roberts use. Demonstrating the benefits of a KEW policy quantitatively is a useful contribution of the present paper.

3. Specifically, the difference in the policy rate depends on an average of the output gap and the divergence of inflation from its target. Thus, no matter how low the initial level of the policy rate, the central bank is assumed to increase it only when inflation and output are close to target, on average. 
So is the ELB problem solved? The answer, I think, is not quite yet. In their simulations, Kiley and Roberts always posit model-consistent (or "rational") expectations. This is the right base case, and it provides a plausible basis for comparing policies across alternative steady states. However, by assuming away the important question of how private sector expectations are formed, particularly outside the steady state, Kiley and Roberts avoid not only the problem of imperfect central bank credibility - an issue the authors discuss, and which has been extensively analyzed in the literaturebut also a range of other questions bearing on the efficacy of central bank communication. I give a few examples below of why better understanding of how markets and the public process information, including central bank talk, is of great practical importance for the issues that Kiley and Roberts are investigating.

CHANGES IN THE MONETARY POLICY REGIME Steady-state comparisons under model-consistent expectations offer little guidance about how to make the shift from one policy regime to another. In particular, Kiley and Roberts analyze a hypothetical scenario in which they consider how the U.S. economy might have performed in 2013 (that is, during the recent ELB episode) if their favored shadow rate policy had been in place. It is particularly important that their analysis should not be taken as implying that the Federal Open Market Committee (FOMC) in 2013 could have executed this policy shift in real time: The public would have been unlikely to understand the FOMC's explanations of the shadow rate regime-or, if they understood it, to have found it fully credible in the short run. In particular, because the shadow rate regime governs the evolution of the policy rate only after the exit from the ELB episode, in 2013 the FOMC would not have been able to take any explicit action (other than talk) to signal the shift. I agree that central bank talk can have real effects, as the Fed's experience with forward guidance suggests. But it seems likely that there are limits, at least in the short run, on a central bank's ability to manage expectations. ${ }^{4}$

FRAMING AND EXPLAINING THE MONETARY POLICY REGIME Alternative monetary policy regimes, even those that have similar effects in simulation models with model-consistent expectations, can be framed in different ways. For example, formally raising the central bank's inflation target, or keeping the inflation target unchanged but risk-adjusting it—both policies analyzed here-are very similar in substance. Is there any basis for choosing between them based on ease of explanation? Likewise, as Kiley and Roberts

4. Hausman and Wieland $(2014,2015)$ document the difficulties that the Bank of Japan has had in lifting inflation expectations, despite its aggressive policies. 
point out, their favored shadow rate policy (which can be explained as a sort of forward guidance regarding interest rates) can also be framed as a form of flexible price level targeting. In practice, how a policy is explained, and the audiences at which the explanation is directed, are likely to be important determinants of its effectiveness.

STRUCTURING FORWARD GUIDANCE During the recent ELB episode, the Federal Reserve was able to influence longer-term interest rates through forward guidance, both qualitative (promising that rates would be low "for an extended period") and quantitative (tying future rate policy to specific dates or to unemployment and inflation thresholds). There has been a lively debate about the efficacy of such policies, with defenders arguing that they approximated KEW lower-for-longer policies and with critics contending that the Fed's statements could be interpreted as forecasts of a weak economy, which, by adding to private sector pessimism, were contractionary on net. ${ }^{5}$ This debate has largely focused on the responses of financial markets and of professional economic forecasters to announcements by the Fed, but other beliefs matter as well. For example, some actors may be unaware of the Fed's communications but able to see changes in interest rates and prices directly relevant to their decisions. A potential homebuyer, for example, might respond to lower mortgage rates irrespective of the nature of the Fed's communications that led bond investors to bid rates down. Kiley (2017) looks at the impact of monetary policies in a world where the expectations of financial market participants are rational but businesses and households form expectations adaptively (and thus cannot be directly influenced by central bank communications).

I have occasionally observed that monetary policy is 98 percent talk and 2 percent action, an aphorism that seems even more apposite at the ELB. Making monetary policy more effective will therefore require making central bank communication more effective. Attaining better understanding of how central banks talk and how (and by whom) their messages are received will not be easy, and will require economists to look more carefully at survey data (Coibion, Gorodnichenko, and Kamdar 2017) and at historical episodes as well as formal models. But this understanding will be necessary

5. Campbell and others (2012) distinguish "Delphic" from "Odyssean" forward guidance. In Delphic forward guidance, which is contractionary, the central bank's expectation for low interest rates reflects its expectation that the economy will be weak. Odyssean forward guidance is a KEW policy, in which the central bank promises to keep rates low even as the economy improves. Femia, Friedman, and Sack (2013) and Swanson (2017) find that the Federal Reserve's forward guidance of recent years has been effective in easing financial conditions. 
to make confident policy recommendations in a world where the ELB is more relevant than in the past.

\section{REFERENCES FOR THE BERNANKE COMMENT}

Abrahams, Michael, Tobias Adrian, Richard K. Crump, and Emanuel Moench. 2015. "Decomposing Real and Nominal Yield Curves." Staff Report no. 570. Federal Reserve Bank of New York.

Bernanke, Ben S., Vincent R. Reinhart, and Brian P. Sack. 2004. "Monetary Policy Alternatives at the Zero Bound: An Empirical Assessment." Brookings Papers on Economic Activity, no. 2: 1-78.

Campbell, Jeffrey R., Charles L. Evans, Jonas D. M. Fisher, and Alejandro Justiniano. 2012. "Macroeconomic Effects of Federal Reserve Forward Guidance." Brookings Papers on Economic Activity, Spring: 1-54.

Coibion, Olivier, Yuriy Gorodnichenko, and Rupal Kamdar. 2017. "The Formation of Expectations, Inflation and the Phillips Curve.” Working Paper no. 23304. Cambridge, Mass.: National Bureau of Economic Research.

Del Negro, Marco, Domenico Giannone, Marc P. Giannoni, and Andrea Tambalotti. 2017. "Safety, Liquidity, and the Natural Rate of Interest." In the present volume of Brookings Papers on Economic Activity.

Eggertsson, Gauti B., and Michael Woodford. 2003. "The Zero Bound on Interest Rates and Optimal Monetary Policy." Brookings Papers on Economic Activity, no. 1: 139-211.

Evans, Charles, Jonas Fisher, François Gourio, and Spencer Krane. 2015. "Risk Management for Monetary Policy Near the Zero Lower Bound." Brookings Papers on Economic Activity, Spring: 141-96.

Femia, Katherine, Steven Friedman, and Brian Sack. 2013. "The Effects of the Policy Guidance on Perceptions of the Fed's Reaction Function.” Staff Report no. 652. Federal Reserve Bank of New York.

Fernald, John G., Robert E. Hall, James H. Stock, and Mark W. Watson. 2017. "The Disappointing Recovery of Output after 2009." In the present volume of Brookings Papers on Economic Activity.

Fleming, Michael, and John Sporn. 2013. "How Liquid Is the Inflation Swap Market?" Liberty Street Economics blog post, April 1. Federal Reserve Bank of New York.

Hausman, Joshua K., and Johannes F. Wieland. 2014. "Abenomics: Preliminary Analysis and Outlook." Brookings Papers on Economic Activity, Spring: 1-63.

—. 2015. "Overcoming the Lost Decades? Abenomics after Three Years." Brookings Papers on Economic Activity, Fall: 385-413.

Kiley, Michael T. 2017. "The Power of Interest-Rate Forward Guidance When Households and Businesses Are Not Very Forward-Looking." Working paper. https://www.dropbox.com/s/3fx8s2kkc47y1bh/frbcommit.pdf?dl=0

Krugman, Paul R. 1998. "It's Baaack: Japan's Slump and the Return of the Liquidity Trap.” Brookings Papers on Economic Activity, no. 2: 137-87. 
Survey of Primary Dealers. 2017. "Responses to Survey of Primary Dealers." Federal Reserve Bank of New York. https://www.newyorkfed.org/medialibrary/ media/markets/survey/ 2017/Mar-2017-SPD-Results-Public-Release.pdf

Survey of Professional Forecasters. 2017. "First Quarter 2017 Survey of Professional Forecasters." Federal Reserve Bank of Philadelphia. https://www. philadelphiafed.org/research-and-data/real-time-center/survey-of-professionalforecasters/2017/survq117

Swanson, Eric T. 2017. "Measuring the Effects of Federal Reserve Forward Guidance and Asset Purchases on Financial Markets." Working Paper no. 23311. Cambridge, Mass.: National Bureau of Economic Research.

Williams, John C. 2009. "Heeding Daedalus: Optimal Inflation and the Zero Lower Bound." Brookings Papers on Economic Activity, Fall: 1-37.

Woodford, Michael. 2009. "Comment on 'Heeding Daedalus: Optimal Inflation and the Zero Lower Bound." Brookings Papers on Economic Activity, no. 2: $38-45$.

GENERAL DISCUSSION Although previous research had shown the zero lower bound to be an interesting issue, John Williams believed the present paper proved it was also a terrifying issue. He was very sympathetic to discussant Ben Bernanke's comments, which pushed back on how extremely negative some of the results of the paper were. For example, one might believe that if the zero lower bound is a major constraint on monetary policy, its effects are going to show up everywhere in the economy, through large first-order effects on economic dynamics. However, Williams pointed to joint work with Eric Swanson, which found that the response of medium- and longer-term interest rates, such as 5- and 10 -year Treasury yields, to economic news did not change at the zero lower bound. ${ }^{1}$ Swanson and Williams's interpretation was that there is an understanding by market participants that the Federal Reserve or other policymakers would step in and do whatever it takes to offset a very negative event, through quantitative easing, forward guidance, unconventional monetary policy, or perhaps even fiscal policy.

Furthermore, looking at options data on distributions and beliefs about interest rates and inflation through swaps, it is clear that market participants think the U.S. economy is going to hit the zero lower bound in the future, Williams stated. Options data on inflation swaps show that the mean and

1. Eric T. Swanson and John C. Williams, "Measuring the Effect of the Zero Lower Bound on Medium- and Longer-Term Interest Rates," American Economic Review 104, no. 10 (2014): $3154-85$. 
median are moving down, though the distribution in terms of the options has not changed much around the mean. In fact, the variance or the standard deviation of inflation from options has been shrinking over the last several years, he noted, which indicates that inflation has not been as big a problem in the zero lower bound period as is implied by Kiley and Roberts.

Finally, Williams noted how hard it was to convince people that the Federal Reserve was really going to keep interest rates low for a long period. In his paper with Swanson, they document that expectations were that the Federal Reserve was going to raise rates in under 18 months during 2009 and 2010. It was not until the August 9, 2011, meeting of the Federal Open Market Committee (FOMC) that strong statements about forward guidance really aligned market expectations with the lower-for-longer policy. That experience was like a test case, Williams thought, of the challenges involved in sticking with a policy that has not been tried before. It also showed that forward guidance can be a very powerful tool in a situation like that to bring expectations into alignment with policy objectives.

Narayana Kocherlakota pushed back on comments made by Williams about forward guidance, stating that he believed forward guidance was used effectively by the FOMC, but did not believe the FOMC used commitment along the lines suggested by Gauti Eggertsson and Michael Woodford or Paul Krugman in the last zero lower bound episode, and was skeptical that the FOMC would ever use commitment to the extent suggested by Kiley and Roberts. ${ }^{2}$ He believed today that the Federal Reserve was in a good position in terms of market-based measures of its credibility. One year earlier-before the Federal Reserve raised interest rates for the first time after the 2008-09 financial crisis-the conversation might have been different. When interest rates are close to zero, the Federal Reserve's credibility about its ability to hit inflation and employment objectives is likely to be a matter of doubt, he contended.

Kocherlakota also suggested that the authors contemplate lowering the lower bound in their model to -50 or -75 basis points. He has found doing so to be surprisingly effective in some of his own work. It is much like raising the inflation target, he noted; especially if the economy is having a long stay at the zero lower bound, one should think about cumulating the lowering

2. Gauti B. Eggertsson and Michael Woodford, "The Zero Bound on Interest Rates and Optimal Monetary Policy," Brookings Papers on Economic Activity, no. 1 (2013): 139-211; Paul R. Krugman, "It's Baaack: Japan's Slump and the Return of the Liquidity Trap," Brookings Papers on Economic Activity, no. 2 (1998): 137-87. 
of the effective lower bound over many years as a way of buttressing the economy. Pushing down long-term rates is what matters.

Finally, Kocherlakota thought it was useful to back up from the technical language of "zero lower bound" and "effective lower bound" and to think about the economics of it all. Economic theory suggests that the zero lower bound is a problem created by the existence of government-provided currency as a store of value: The government provides a store of value with a nominal interest rate of zero to its citizens. If that were to be eliminated, the problem would be eliminated, he contended. As economists, this is an argument to get rid of currency, or at least to limit high-denomination notes, as had been suggested by Kenneth Rogoff and Miles Kimball. ${ }^{3}$ Alan Blinder completely agreed with Kocherlakota's assessment.

William English believed it was important, in practice, to think about other monetary policy tools, such as asset purchases. The authors, in effect, focus only on forward guidance. A recent paper by David Reifschneider suggested that at the zero lower bound, asset purchases might be a good substitute for lower short-term rates. ${ }^{4}$ There is more work to be done on the topic, but it is a direction he wanted explored more.

Benjamin Friedman had three observations. First, he believed an interesting element of the paper to which the authors did not pay much attentionbut one that might be worth developing - is the existence of the variable on the right-hand side of their equation 1 representing the change in the output gap. The inclusion of the term in the monetary response function is helpful because it prevents the central bank from tightening too quickly in a recovery period. He pointed to an older body of economic control literature, in which having the rate of change of a target variable on the right-hand side of what in those days was called a feedback rule had very important stabilizing properties. The authors' model seemed to him to be a nice illustrative example of this familiar result, precisely because it provided a structural story about why the principle works.

Friedman's second observation was a reinforcement of what Bernanke said about the lack of substantive differences between Kiley and Roberts's policy recommendation of risk management, and the idea of having a higher inflation target; the two are in essence the same. In one, the idea is to keep

3. Kenneth S. Rogoff, The Curse of Cash (Princeton University Press, 2016); Ruchir Agarwal and Miles Kimball, "Breaking Through the Zero Lower Bound," Working Paper no. 15/224 (Washington: International Monetary Fund, 2015).

4. David Reifschneider, "Gauging the Ability of the FOMC to Respond to Future Recessions," Finance and Economics Discussion Series no. 2016-068 (Washington: Board of Governors of the Federal Reserve System, 2016). 
the inflation target at 2 percent but to understand that when it can be done, inflation should be higher than 2 percent. The other is to simply have a higher inflation target but to understand that it often cannot be met. These are in essence the positive and negative ways of expressing the same concept. Implicitly, however, the paper advocates for a higher inflation target. Friedman understood the bureaucratic difficulty of raising the inflation target; the Federal Reserve has somehow locked itself into the notion that because it once said the target was 2 percent, it can never change. But such bureaucratic arguments should be understood for what they are.

Finally, Friedman thought that it might be useful to link this point to a body of literature that used to be called "opportunistic disinflation." If the Federal Reserve aims for 3 percent inflation when it can actually achieve it, the authors assume that something will happen naturally that will bring inflation back down to below 2 percent. This is an important point for credibility, he noted. One of the traditional questions about whether overshooting can be a credible policy is that if the central bank overshoots and gets inflation to be above the target, then there will presumably be costs to getting it back down-if everyone thinks the central bank will be reluctant to foot those costs, then overshooting is therefore not a credible policy. Implicit in the authors' analysis is an assumption that there are no costs to bringing inflation back down: If the Federal Reserve can and does hit 3 percent inflation, something will come along and bring inflation back to 2 percent. Therefore, the overshooting policy implicit in the authors' arguments becomes credible.

Jay Shambaugh was curious about what the authors thought of a minor distinction: whether the 2 percent target is a ceiling or a symmetric target. The Federal Reserve clearly articulates that it is a symmetric target, and that is how the authors treat it; but outside commentators sometimes think the Federal Reserve is treating it as a ceiling, or should be treating it as a ceiling. Other central banks, such as the European Central Bank, statutorily discuss the inflation target more as a ceiling and not a symmetric target. It would seem the authors could show just how big a difference this subtle distinction makes, he concluded.

Steven Braun asked if the authors were making underlying assumptions that asset purchases do not work and that fiscal policy can do nothing to help.

Christopher Carroll noted the importance to the model's results of the rational expectations assumption, which is a problem because nobody (including Bernanke) thinks it is a good description of how expectations are determined in the real world. He amplified this assertion by making 
two points. First, the data that economists tend to look at on the question of how expectations are formed are data from financial markets, but the mechanisms in models like the authors' for how forward guidance or other such expectation-manipulating channels work are largely drawn from the behavior of household consumption expenditures. If, in fact, there is a different process for how households behave or form their expectations than financial markets, then these data from financial markets are not particularly helpful. Relatedly, Carroll thought it was "frankly, kind of a scandal" that there is almost no literature systematically proposing, testing, refuting, or supporting alternative models of how people form their expectations.

Athanasios Orphanides noted that though the zero lower bound is a problem, it may not be as bad a problem as the authors suggest, for the reasons implied by English and Braun: Quantitative easing does not seem to play a role in the authors' theory. This reminded Orphanides of Bernanke's statement three years earlier that the problem with quantitative easing is that it works in practice but not in theory. ${ }^{5}$ The theory is reflected in the authors' models, but in reality quantitative easing actually does work. Quantitative easing - as practiced by the Federal Reserve since the beginning of the financial crisis, by the Bank of England, and by the Bank of Japan since 2013 - is extremely powerful, he argued, and this is why the zero lower bound is not as big an issue. It matters which view one takes before discussing whether inflation targets should be raised. A second point Orphanides raised was that the authors' results seemed to be too sensitive to exactly how policy is implemented. The Taylor rules used by the authors are great for some obligations, but at the zero lower bound one could consider alternative simple rules. Orphanides and Volker Wieland, in their research during the late 1990s on the Japanese experience, proposed a policy whereby a central bank could control the interest rates on government bonds. ${ }^{6}$ In September 2016, the Bank of Japan implemented a policy of quantitative easing with "yield curve control," so the 10-year yield effectively acts as an instrument.

5. Ben Bernanke, "A Discussion with Federal Reserve Chairman Ben Bernanke on the Fed's 100th Anniversary," remarks at Central Banking after the Great Recession: Lessons Learned and Challenges Ahead, Brookings Institution, Washington, January 16, 2014 (https://www.brookings.edu/wp-content/uploads/2014/01/20140116_bernanke_remarks_ transcript.pdf).

6. Athanasios Orphanides and Volker Wieland, "Efficient Monetary Policy Design Near Price Stability," Journal of the Japanese and International Economies 14, no. 4 (2000): 327-65. 
Andrea Tambalotti made a simple point about the potential transition from current policy to a rule that looks something like what the authors suggest. In his view, there is more continuity between current policy and a more history-dependent policy, like the one suggested by the authors, than is commonly believed. Current policy already has a high degree of history dependence, which blurs the line between inflation targeting and price level targeting. In practice, the difference between the two policy approaches is one of communication, he stated. This observation does not address Bernanke's point about the possible reaction of the public expectations to such a change in communication; but the change essentially boils down to this question: As interest rates rise, will the Federal Reserve try to glide into 2 percent inflation, or will it allow for the possibility of an overshoot? Thinking in these terms makes the difference between the current policy regime and a regime that looks like the one described in the paper fairly small, he concluded.

Jonathan Wright suggested that another approach to avoiding the problem of the zero lower bound is to lower term premiums through asset purchases, which may be more politically feasible than raising the 2 percent inflation target. He recalled a paper by Kiley in which he argued that a drop in longterm interest rates brought about by a decline in the term premium has an effect on aggregate demand that is about half as large as a drop in long-term interest rates caused by a lowering of the federal funds rate. ${ }^{7}$ So though it may not be as powerful a tool, lowering term premiums still has some effect and is potentially politically feasible. Wright noted that the 2 percent forward breakeven inflation rates were not sending a market-based signal of great concern, but that they are still consistent with the idea that there is some worry about undershooting an inflation target, since breakevens are based on the consumer price index, not personal consumption expenditures, and since evidence from Treasury inflation-protected securities supports the notion that inflation risk premiums normally outweigh liquidity premiums.

Emi Nakamura followed up on comments made by Kocherlakota and reiterated by Blinder about there being an issue with the government providing a store of value in the form of currency, which earns no interest. In her view, the issue with the zero lower bound has more to do with the fact that cash is a unit of account rather than a store of value. Her intuition about the problem of the zero lower bound is that shocks in the economy cause the real interest rate to fall, but often prices do not respond. If nominal interest

7. Michael T. Kiley, "Aggregate Demand Effects of Short- and Long-Term Interest Rates," International Journal of Central Banking 10, no. 4 (2014): 69-104. 
rates are fixed at zero, then in the face of a recessionary shock, according to the real business cycle model, prices should jump down instantaneously, then start to rise. The subsequent rise leads to a reduction in the real interest rate. But if prices do not jump, she noted, what seems to happen is that inflation is low and real interest rates actually rise, which is the opposite of what is supposed to happen in the real business cycle model. Therefore, the fundamental issue is that the unit of account-the price level—does not jump, she concluded.

Eric Swanson noted that just touching the zero lower bound is not really a problem in the authors' models; in order to have any important effects, the zero lower bound must constrain the short-term interest rate for several quarters. For example, Lawrence Christiano, Martin Eichenbaum, and Sergio Rebelo find that the zero lower bound needs to bind for about eight quarters or more to have any significant effect on their model. ${ }^{8}$ Kiley and Roberts find that the zero lower bound binds about 40 percent of the time; Swanson posited that a much more relevant statistic would be how often the zero lower bound binds for, say, eight quarters or more. Tying into Kocherlakota's point about negative interest rates, Swanson further noted that what is relevant is not whether the federal funds rate would be zero for eight quarters, but rather whether it would fall all the way down to -50 or -75 basis points for eight quarters or more. That is going to happen much less frequently than 40 percent of the time in the authors' models, he contended. Finally, on the question of the effectiveness of forward guidance and asset purchases, Swanson pointed to his recent work showing that asset purchases actually work very well, which makes the zero lower bound even less of a concern. He concluded by saying that there seem to be enough tools to work around the problem of the zero lower bound without having to raise the inflation target.

James Stock noted that there seems to be a large body of evidence that the natural rate of interest has fallen, which increases the likelihood of hitting the zero lower bound. There also seems to be copious evidence that a change in a policy rule can potentially improve welfare. The challenge, in his view, is how such a change should be implemented in a credible way, which seems more like a process question than an economic one. The Federal Reserve's shift toward increasing transparency started under Chairman Ben Bernanke and has continued under Chair Janet Yellen. In the spirit of openness, he thought it might be a good idea for the Federal Reserve to go

8. Lawrence Christiano, Martin Eichenbaum, and Sergio Rebelo, "When Is the Government Spending Multiplier Large?” Journal of Political Economy 119, no. 1 (2011): 78-121. 
through, say, a five-year review of policy, much like the Bank of Canada. Such a review would engage the academic community, so a decision would not be arbitrary; it could consider questions like raising the inflation target and even eliminating cash.

Kiley thought that the kind of steady-state analysis the authors were doing was helpful because, if one were to consider a policy such as raising the inflation target, one would want to know what the benefits would be if it were pursued in the steady state. He agreed that transitional issues are also interesting, and noted that he and Roberts have both done research on these questions.

Roberts noted that the authors did not consider the effects of negative interest rates or quantitative easing because there are models that suggest quantitative easing in particular is less effective than one might hope. If the Federal Reserve is willing to increase its balance sheet by, say, $\$ 4$ trillion, the unemployment rate in the next recession might be a few tenths of a percentage point lower, which would not solve the problem, in his estimation. He agreed with the points made by Tambalotti and Williams that commitment strategies can be effective and that further moves in that direction could be beneficial. He recalled Wright's argument that financial markets seem to be afraid of low inflation for an extended period of time, which may indicate that these markets fear the low-inflation outcomes highlighted in the paper, especially given that at the time of writing, the U.S. unemployment rate was roughly 4.5 percent, which is about as good as it gets. 